\title{
A Hybrid Computational Method of Desirability, Fuzzy Logic, ANFIS, and LAPO Algorithm for Multiobjective Optimization Design of Scott Russell Compliant Mechanism
}

\author{
Ngoc Thoai Tran, ${ }^{1}$ Ngoc Le Chau, ${ }^{1}$ and Thanh-Phong Dao $\mathbb{D}^{2,3}$ \\ ${ }^{1}$ Faculty of Mechanical Engineering, Industrial University of Ho Chi Minh City, Ho Chi Minh City, Vietnam \\ ${ }^{2}$ Division of Computational Mechatronics, Institute for Computational Science, Ton Duc Thang University, Ho Chi Minh City, \\ Vietnam \\ ${ }^{3}$ Faculty of Electrical \& Electronics Engineering, Ton Duc Thang University, Ho Chi Minh City, Vietnam
}

Correspondence should be addressed to Thanh-Phong Dao; daothanhphong@tdtu.edu.vn

Received 18 January 2020; Revised 4 April 2020; Accepted 6 April 2020; Published 27 April 2020

Academic Editor: Eric Florentin

Copyright (C) 2020 Ngoc Thoai Tran et al. This is an open access article distributed under the Creative Commons Attribution License, which permits unrestricted use, distribution, and reproduction in any medium, provided the original work is properly cited.

\begin{abstract}
Flexure-based compliant mechanisms are increasingly promising in precision engineering, robotics, and other applications, thanks to the excellent advantages of no friction, no backlash, no wear, and minimal assembly. However, their design and analysis are still challenging due to the coupling of kinematic-mechanical behaviors with large nonlinear deflections in comparison to their rigid-body counterparts. Optimal design is an important aspect in the field of compliant mechanisms and has attracted much attention during the last decades. Especially, when considering a multiobjective optimization design for compliant mechanisms, the problem is becoming more complicated. Thus, this article presents a new efficient hybrid computational method to resolve multiobjective optimization design of compliant mechanisms. A Scott Russell compliant mechanism is employed as the design example and to show the advantages of the proposed optimizing method. The proposed method is developed by hybridizing the desirability function approach, fuzzy logic system, adaptive neuro-fuzzy inference system (ANFIS), and lightning attachment procedure optimization (LAPO). First of all, a 3D finite element model is created and central composite design is employed to build a numerical matrix. First, design variables are refined by using analysis of variance and Taguchi approach in terms of considerably eliminating space of design variables. Subsequently, desirability values of two objective functions are determined and transferred into the fuzzy logic system. The output of the fuzzy logic system is considered as a single combined objective function. Next, modeling for fuzzy output is established via developing the ANFIS model. At last, the LAPO algorithm is adopted for solving the multiobjective optimization problem for the mechanism. Three numerical examples are investigated to validate the feasibility and the effectiveness of performance efficiency of the proposed methodology. The results find that the proposed methodology is more efficient than traditional Taguchi-based fuzzy logic. Besides, the performance efficiency of the proposed approach outperforms the Jaya algorithm and TLBO algorithm through the Wilcoxon signed rank test and Friedman test. The results of this article give a useful approach for complex optimization problems.
\end{abstract}

\section{Introduction}

Scott Russell compliant mechanism (SRCM) is utilized as a shuttle to transform two input motions into output one. It is exerted by a piezoelectric actuator in applications of high precision positioning systems. The mechanism can achieve its performances through elastic deformation of flexure hinges [1-4]. It benefits a monolithic structure, lightweight, and free friction. Nonlinear behaviors of the mechanism are facing challenges for researchers in compliant mechanism. Over the past several decades, researchers have tried to make approaches and methods to synthesize compliant mechanisms, e.g., kinematic-based methods [5-8]. They showed that physical behaviors and performances of compliant mechanism should analyze displacement, stress, frequency, and parasitic error. Kinematic-based methods are still valid, but some are difficult to resolve the performances of SRCM because of their complicated applications. 
In the past decades, a lot of analytical methods and numerical methods have been proposed for designing and analyzing compliant mechanisms, such as the pseudorigidbody model (PRBM) [9], Castigliano's second theorem [10], compliance matrix method [11], empirical method [12], beam constraint model [13], Euler-Bernoulli beam theory [14], and finite element method [15]. However, these methods are useful in advancing simple compliant mechanisms with existing configurations. But they are critically challenging in analyzing the static and dynamic behaviors for complex compliant mechanisms, such as irregular shapes of flexure hinges and complex configurations and large deflections. It is known that the PRBM is still a valuable technique for modeling, but it is limited in highly nonlinear deformation of flexure hinges. For complex loads and complicated configurations of flexure hinges, the PRBM is not suitable. Especially, the PRBM is strongly dependent on the location of torsional springs, the number of torsional springs, and designer's experiences in the field of compliant mechanisms. Castigliano's second theorem can analyze the strain energies of flexure hinges such as tensile, shear, and bending strains, but this theorem is critically complicated for complex structures. Compliance matrix method is actually difficult for analyzing when compliant mechanisms subject multiple complicated actuation forces. Elastic beam theory is related to the deformation energy of compliant mechanisms, but it is still complicated for complex structures. Based on the two-port dynamic stiffness model, statics and dynamics can be effectively solved, but it becomes more complicated for modeling irregular structures. Compliance matrix method is used to transfer the compliance of flexure hinges from the local coordinate frame into a reference coordinate system. This method is still complicated for a more complex structure of compliant mechanisms. Empirical modeling can analyze compliant mechanisms with high accuracy, but it is very costly and time-consuming. It is difficult to analyze a large deformation of flexure hinges using the beam constraint model. Finite element method (FEM) analyzes complex geometric shapes of compliant mechanisms by discretizing compliant mechanisms into elements and nodes.

Although the previous methods are still valid, they are still challenging to analyze the complex compliant mechanisms. The estimating accuracy of modeling are based on a complexity degree of kinematic and mechanical coupling of compliant mechanisms. Especially for a large nonlinear deflections and irregular shapes, the abovementioned methods are limited. For optimal design of multiple performances of compliant mechanisms, the problem is becoming more complex. Therefore, data-driven approach, computing intelligence, and machine learning have attracted much attention to model complex systems [16-18]. Datadriven approaches-coupled computing intelligence is an effective tool that has not extended to the field of compliant mechanisms yet. From reviewing the literature review, the motivation of this article is to develop a new hybrid computational method to solve the optimal design for compliant mechanisms. The proposed method is extended to solve for most compliant mechanisms from a basic structure to a complex one. Specifically, it is an efficient approach for the SRCM. In order meet wide applications, the SRCM requires both a large displacement, a high frequency, and a good enough working strength. In order to solve three quality performances simultaneously, size, shape, or topology of the proposed mechanism can be changed. However, a such random change spends a lot of computational time. At the same time, a parameter optimization is conducted by researchers to enhance the physical performances. Optimization problem includes a single response or more than two ones. In the past, the structural optimization problem of a compliant mechanism separates into three main types, e.g., topology optimization [19], shape optimization, and size optimization $[14,20,21]$. In this work, size optimization is chosen to find the best geometrical parameters of SRCM.

In order to solve multiple objective responses, a multiobjective optimization (MOO) problem is investigated. The aim of the MOO problem is to reach a trade-off between characteristics. Nowadays, the MOO problem has received a great interest for compliant mechanisms [22-24]. However, a MOO optimal design for the proposed SRCM has not been studied in depth. So, parameter optimization is proposed in the present article. In a real structure of SRCM, it includes possible design parameters affecting desired performances. Besides, it is well-known that physical behaviors of the SRCM are very sensitive to a change in shape, material, or geometrical parameters. Shape and material may be directly varied according to customer's demands. Meanwhile, structural parameters should be optimized to improve the performances. The most critical parameters strongly contribute on the performances, while some nonsignificant parameters lead high computational cost. Hence, before implementing the MOO process, this study determines the most significant design variables and nonsignificant parameters.

Basically, before dealing with a MOO problem for a specific compliant mechanism, a mathematical model is expected to be established through kinematic-based analytical approaches such as pseudorigid-body model [25], semianalytical model [26], and compliance matrix [27]. Although mentioned approaches are still used, they are complicated for modeling the SRCM. In other words, analytical methods are limited to feature its behaviors of more complex structures. In order to avoid an imprecise optimization solution since approximate approaches may be complicated, data-driven approaches are more advantageous to adopt for the MOO problem. Data-driven approach is utilized to directly map the inputs and outputs data; therefore, this approach has a good predicting accuracy in comparison with the analytical methods. During the last decades, a lot of methods have been developed to solve the MOO problems, such as desirability function approach (DFA) [28], grey relational analysis (GRA) [29], Taguchi method-based fuzzy logic (TMFL) [30]. Both DFA and GRA need a weight factor for each objective function, but weighting factor is largely dependent on experience or users. Meanwhile, TMFL is a statistical-based approach without the weight factor. Although TMFL has more benefits, it searches optimal values at discrete points from the Taguchi 
method. In order to avoid a local result, surrogate models are employed to connect inputs and outputs, e.g., response surface method (RSM) [31], Kriging technique [32], artificial neural network (ANN) [33-35], adaptive neuro-fuzzy inference system (ANFIS) [36-38], RSM-ANN [39], ANN machine learning [40], and fuzzy logic theory [41]. Among them, ANFIS is proved as an effective technique to modeling and predicting, which is applied for different engineering fields. For example, ANFIS was developed to predict for various fields, e.g., the hydropower generation [17], the scour hole shape [18], and mercury emissions in combustion flue gases [42]. However, ANFIS has not extended for modeling the Scott Russell compliant mechanism yet.

Up to now, nature-based metaheuristic algorithms have been developing very fast, e.g., genetic algorithm [43], particle swarm optimization (PSO) [44], differential evolution [45], cuckoo search algorithm [46], and other algorithms [47-50]. Some of them have successfully been applied in various fields, such as grey wolf optimization for temperature-based oil-water relative permeability [16] and PSO algorithm for predicting the scour depth around bridge piers [51]. More recently, several algorithms with less or nontuned parameters have been suggested such as teaching learning-based algorithm (TLBO) [52, 53], Jaya algorithm [54], and lightning attachment procedure optimization (LAPO) algorithm [55]. Among three less-parameter algorithms, LAPO algorithm is an effective approach for a lot of engineering areas, but it has not been applied for the SRCM mechanism yet. Therefore, this article chooses the LAPO algorithm to extend the MOO design. In summary, highlight contributions of this study are as follows: (i) limit nonsignificant parameters and refine space of design variables; (ii) transfer the desirability value of objective functions into the fuzzy logic reasoning; (iii) develop the ANFIS structure to model the output of FIS system; (iv) LAPO algorithm is proposed for implementing the MOO problem to find global solution; (v) performances of proposed methodology are compared with other algorithms using statistical techniques.

The goal of this article is to develop new hybrid computational methodology to conduct MOO optimal design for the SRCM mechanism. As mentioned above, the proposed method is considered as statistical-based intelligent computation. A 3D model is created by the finite element method, and central composite design is employed to make design of experiments. Initial space of design variables is determined and then refined via analysis of variance and Taguchi technique. New spaces of design parameters are generated through sensitivity investigation. Next, desirability values of quality responses are calculated and transferred into the fuzzy logic system. ANFIS technique is developed to connect design variables and output of the FIS. MOO problem is then solved by using the LAPO algorithm. Numerical examples are investigated to evaluate the computational efficiency and performance of proposed method. In addition, performances of the proposed approach are compared with the ANFIS-based Jaya and ANFIS-based TLBO by implementing the Wilcoxon signed rank test and Friedman test.

\section{Proposed Hybrid Methodology}

Figure 1 describes a new computational method which is hybridized by the integrating desirability approach, fuzzy logic reasoning, ANFIS, and LAPO algorithm. The proposed method is applied to solve a MOO design for a Scott Russell compliant mechanism. Practically, this mechanism is combined with a piezoelectric actuator (PA) for use in ultrahigh precision positioning devices. Because the PA limited its travel and responding speed, the mechanism needs to improve its displacement and a high natural frequency. In addition, a small equivalent stress is considered as an additional constraint to ensure a good working strength. According to background of compliant mechanism, these specifications are very sensitive to geometrical parameters of flexure hinges. In other words, a change in any geometrical factor may lead to a change in performances. In order to achieve an improvement in performances, design parameters are optimized simultaneously. Proposed hybrid methodology consists of five main phases as follows: (i) design and analysis, (ii) desirability calculation, (iii) fuzzy logic system analysis, (iv) ANFIS modeling, and (v) conduct MOO problem by LAPO algorithm.

2.1. Phase 1: Design and Analysis. This phase concerns about a mechanical design and analysis problem. In this study, a MOO design for a SRCM is investigated. It is an example to show effective application to validate the performance effectiveness of proposed methodology. This phase experiences the following main steps.

\section{Step 1. Mechanical structure}

As discussed above, the mechanism needs a large displacement and a high frequency but must guarantee a small stress for a long operation without plastic failure.

\section{Step 2. Define initial design variables}

Structure of the mechanism has a lot of possible geometrical parameters affecting the quality responses. Such influences must be considered before implementing further the optimization process. Some factors with actual influences as well as no influences are evaluated through sensitivity investigation in this study.

\section{Step 3. Define quality responses}

After determining the initial design variables, a large displacement and a high frequency are assigned as two desired outputs. In order to satisfy in terms of enough working strength, equivalent stress is an extra constraint.

\section{Step 4. Create 3D finite element model}

A 3D finite element model (FEM) is created, and then finite element analysis (FEA) is implemented to retrieve numerical data. To complete this work, design variables and quality responses are assigned to be parametric factors during FEA simulations. 


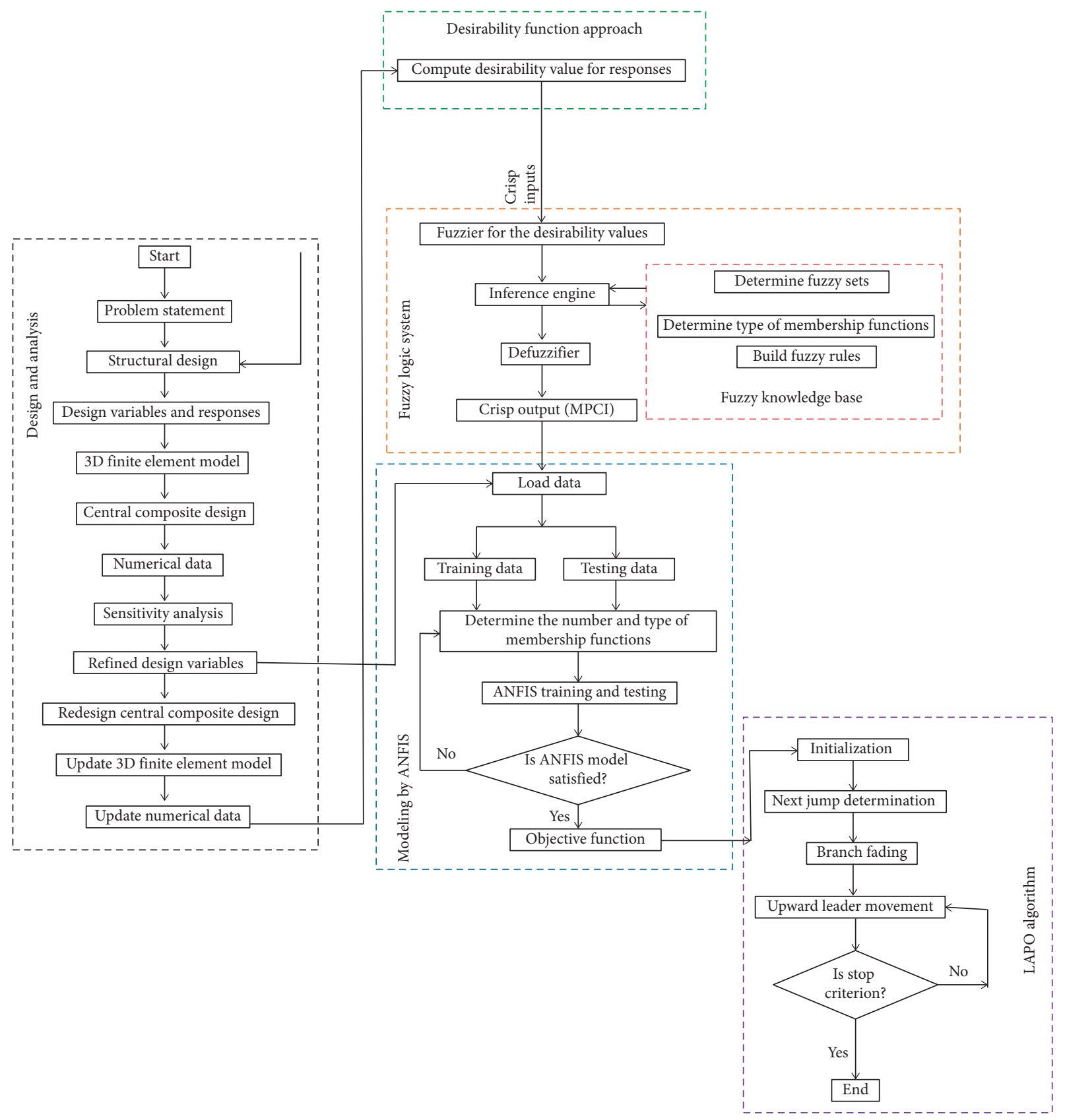

FIGURE 1: Flowchart of proposed hybrid methodology for multiobjective optimization design.

Step 5. Central composite design

While a $3 \mathrm{D}$ model is created, an experimental matrix is also initialized by using central composite design (CCD). Face centered is used in this work.

Step 6. Run numerical data

Boundary conditions, load, and material are set up for the 3D model. Subsequently, a set of numerical data is collected by running simulations.

Step 7. Sensitivity analysis

This is a critically important step. It determines several parameters directly affecting the quality characteristics to be design variables. Besides, some parameters with no influence are ignored. This process is conducted through analysis of variance (ANOVA) and the Taguchi method.

Step 8. Eliminate design variables

The results of sensitivity analysis in Step 7 identify some nonsignificant parameters. And then, such parameters are ignored or eliminated while other important factors are defined as key design variables. The results of refining parameters perhaps create several new population spaces for population-based optimization metaheuristic algorithms. This is a preparing step for further optimization process. The goal of Step 8 is to determine a suitable searching space so as to reduce the computational cost and make more reliable solution. 
Step 9. Repeat central composite design

Several new spaces of design variables are created in Step 8. Each space of refined variables is considered as a case study. And then, Step 9 will rebuild a number of experimental matrixes by using CCD.

Step 10. Refine 3D finite element model

In order to conduct the numerical simulations, a $3 \mathrm{D}$ FEM model is created with respect to each case study. Subsequently, simulations are implemented to get the numerical data for each case study.

\subsection{Phase 2: Desirability Calculation}

Step 11. Recollect numerical data

Numerical data for each of case study are collected through FEA simulations, individually.

Step 12. Compute desirability value for performances

According to theory of the desirability function approach [56], the exponential type is transformed to each response into a desirability function. Principle of this technique is to compute the $i$ th quality response $\left(y^{*}\right)$ to become the $i$ th desirability $\left(d_{i}\right)$, and then all values of desirability are combined into a single desirability function $(D)$. Desirability value can reach unity when the response's target is achieved, and otherwise. Each individual desirability function is divided into three types based on user's specific demand. It includes three target types, i.e., smaller-the-best, higher-the-best, and normal-the-best. Desirability for two specifications of the mechanism is computed. Displacement is millimeter, while natural frequency is in Hertz. Based on calculating the desirability, influence and difference of units are neglected during the optimization process. So, such difference no longer affects later optimal solution.

2.2.1. Smaller-the-Best. The response's value is expected lower than an upper limit. The desirability function is identified by

$$
\begin{cases}d_{i}=0, & y^{*} \geq U_{b}, \\ d_{i}=\left(\frac{y^{*}-U_{b}}{L_{b}-U_{b}}\right)^{r}, & L_{b} \leq y^{*} \leq U_{b}, \\ d_{i}=1, & y^{*} \leq L_{B},\end{cases}
$$

where $d_{i}$ is the desirability value, $y^{*}$ is the ith response, and $L_{b}$ and $U_{b}$ are the lower and upper limits of the response.

2.2.2. Normal-the-Best. The response's value is expected toward a target value $(T)$. The desirability function can be determined by

$$
\begin{cases}d_{i}=\left(\frac{y^{*}-L_{b}}{T-L_{b}}\right)^{p}, & L_{b} \leq y^{*} \leq T, \\ d_{i}=\left(\frac{y^{*}-U_{b}}{T-U_{b}}\right)^{q}, & T \leq y^{*} \leq U_{b}, \\ d_{i}=0, & y^{*} \leq L_{b} \text { or } y^{*} \geq U_{b}, \\ d_{i}=1, & y^{*}=T,\end{cases}
$$

where $p$ and $q$ are specific parameters defined by users ( $p$, $q>0$ ) which determine the shape of $d_{i}$.

2.2.3. Higher-the-Best. The response's value is expected higher than a lower limit. The desirability function can be described by

$$
\begin{cases}d_{i}=0, & y^{*} \leq L_{b}, \\ d_{i}=\left(\frac{y^{*}-L_{b}}{U_{b}-L_{b}}\right)^{r}, & L_{b} \leq y^{*} \leq U_{b}, \\ d_{i}=1, & y^{*} \geq U_{b},\end{cases}
$$

where $r$ is the desirability function index.

All individual desirability's values of responses are transformed into overall desirability, $D$, which is considered as a single quality index. This index is determined by assigning the corresponding weight factor for different quality responses. However, weight factor of each response is dependent on priority or customer's demands. A combined desirability index is computed as

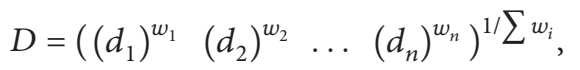

where $D$ is the overall desirability index and $w_{i}$ is the weight of the $i$ th response. $D$ is equal to one as each $d_{i}$ is also equal to one. Otherwise, at least, one of $d_{i}$ is zero and $D$ is zero.

In this paper, a larger type is used for both desired targets (displacement and frequency). Previously, in order to solve a MOO problem, a set of optimal parameters may be found by maximizing the single quality index $D$. Although this approach is still an effective tool, an optimal result is varied when the weight factor of each response is changed. It may result in an imprecisely optimal value. In order to overcome this uncertainty, a fuzzy logic system is then developed to deal with all individual values of desirability of both responses since this system does not require any weight factor.

2.3. Phase 3: Fuzzy Logic Reasoning System. A fuzzy logic reasoning system includes knowledge base, fuzzifier, inference engine, and defuzzifier. Details can be briefly described as follows [57]. 
2.3.1. Fuzzifier. Fuzzifier plays a role to transform real value into a fuzzy system. Inputs of the fuzzy logic system are called as crisp values which contain precise information of a real world. Through the fuzzifier, real value is transformed into linguistic variable.

Knowledge base: knowledge base consists of rule base that forms a number of fuzzy rules (if-then). Moreover, the knowledge base contains a database which defines membership function (MF) of the fuzzy sets.

Inference engine system: based on fuzzy rules, fuzzy inference system (FIS) is considered as decisionmaking. It handles how the rules are combined.

2.3.2. Defuzzifier. It transfers the output of the FIS system into a crisp value. In the defuzzification method, the centroid method is used to the transformation. The output of the FIS system, a nonfuzzy value, is called as a multicharacteristic performance index (MPCI).

In order to implement the FIS system, the Mamdani method is employed in the present paper. Subsequently, trapezoidal MFs are adopted for the inputs and outputs of the FIS so as to form fuzzy sets. MFs are in the range from zero to one, and MFs can describe the way a variable matches a fuzzy set. Inputs and outputs of fuzzification system are then transformed into linguistic variables. The trapezoidal MFs are defined as

$$
\mu_{A}(x, k, l, m, p)= \begin{cases}\frac{(x-k)}{(l-k)}, & k \leq x \leq l, \\ 1, & l<x<p, \\ \frac{(x-m)}{(p-m)}, & p \leq x \leq m, \\ 0, & x \leq k \text { or } m \leq x,\end{cases}
$$

where $\mu_{A}$ denotes the MFs while $k, l, m$, and $p$ are parameters and $x$ is a variable.

In this study, desirability of frequency and desirability of displacement are calculated, and then they are considered as two input variables for the FIS. These linguistic input variables will be combined into an output for the FIS. The trapezoidal MFs are employed for both the fuzzification and defuzzification. The following fuzzy rules are briefly described.

Fuzzy rule: if $x_{1 i}$ is $A_{1}$ and $x_{2 i}$ is $B_{1 i}$, then $y_{i}$ is $C_{i}$ else ( $i=1$, $2,3, \ldots, n)$, where $x_{1 i}$ and $x_{2 i}$ are the two $i$ th inputs and $y i$ is the $i$ th output. $A_{i}, B_{i}$, and $C_{i}$ are defined by corresponding $\operatorname{MFs}\left(\mu_{A i}, \mu_{B i}\right.$, and $\left.\mu_{C i}\right)$, and these parameters are regarded as fuzzy subsets.

In order to compute the fuzzy logic reasoning, max-min operation of Mamdani is adopted. Subsequently, the FIS output is retrieved. The MFs of the FIS output can be described by $\mu_{c i}\left(y_{i}\right)=\max \left[\min \left\{\mu_{A_{1 i}}\left(x_{1}\right), \mu_{A_{2 i}}\left(x_{2}\right), \ldots, \mu_{A_{s i}}\left(x_{s}\right)\right\}\right], \quad i=1,2, \ldots, n$

At last, the FIS output is transformed into real values through the defuzzification. Subsequently, a nonfuzzy value $y_{0}$, which is called as MPCI, is defined by

$$
y_{0}=\frac{\sum y_{i} \mu_{C 0 i}\left(y_{i}\right)}{\sum \mu_{C 0 i}\left(y_{i}\right)} \text {. }
$$

Based on the theory of FIS system, the best solution for overall responses and a set of optimal design variables can be found by maximizing the MPCI index through the Taguchi method. This technique is divided into three types such as (i) higher-the-better, (ii) normal-the-best, and (iii) smaller-thebetter. The larger-the-better type is chosen for maximizing the MPCI, which is described as

$$
\eta=-10 \log \left(\frac{1}{n} \sum_{i=1}^{n} \frac{1}{\mathrm{MPCI}_{i}^{2}}\right)
$$

where $\mathrm{MPCI}_{i}$ is the $i$ th MPCI index and $n$ is the number $i$ th experiment's repetition.

A Taguchi-based fuzzy logic can find optimal candidates in a MOO problem, but this approach may be a local optimum solution. The reason is because the Taguchi technique is employed to minimize or maximize a single fitness function in terms of discrete values. Meanwhile, a real problem desires to search a global optimum solution. In order to overcome such situation, ANFIS is then extended to model the MPCI, and the MOO design for the SRCM mechanism can be effectively solved by using the LAPO algorithm.

2.4. Phase 4: Adaptive Neuro-Fuzzy Inference System. As aforementioned, the FIS system is a modeling technique in terms of linguistic variables where the Mamdani method is used for the FIS. Meanwhile, ANFIS is an artificial technique which is developed by integrating neural network and the FIS. Nowadays, ANFIS is considered as an intelligent modeling which creates a connection between inputs and outputs. In theory of ANFIS, the Sugeno model is employed to create fuzzy rules [58]. The fuzzy rules for the ANFIS model can be defined as

$$
\text { if } x_{1} \text { is } A_{1} \text { and } x_{2} \text { is } A_{2} \text {, then } y=a \times x_{1}+b \times x_{2}+c \text {, }
$$

where $x_{1}$ and $x_{2}$ are inputs with respect to $A_{1}$ and $A_{2}$ term sets, $y$ is the output, and $a, b$, and c are constant values.

Figure 2 illustrates the ANFIS structure which consists of five-layer feed-forward neural network.

Layer 1 is the fuzzification layer that assigns the membership degrees for input factors based on the given MFs. The output of layer 1 can be described as

$$
M_{1}^{i}=\mu A_{i}(x),
$$




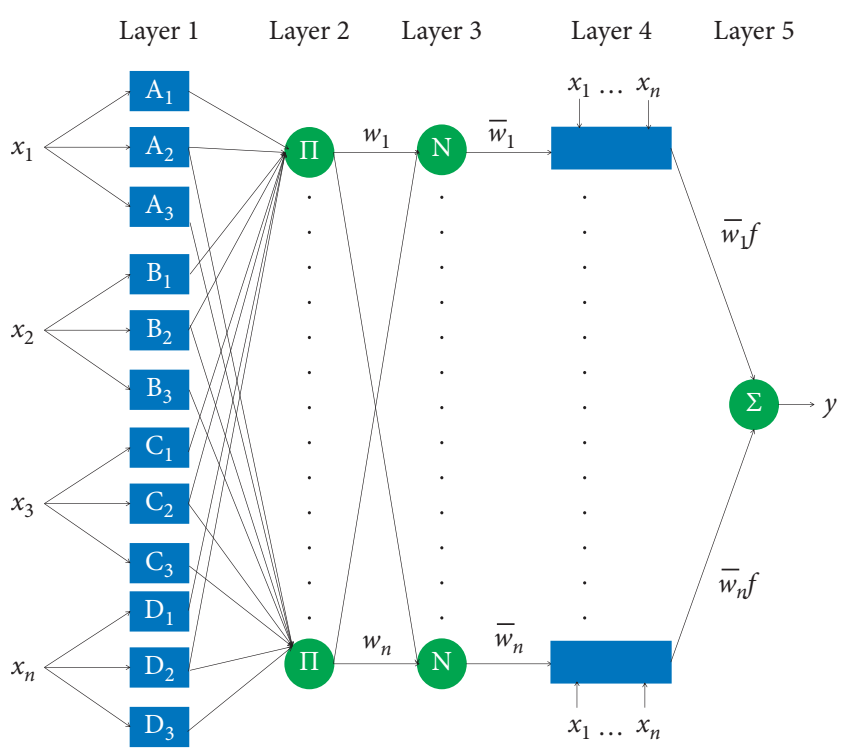

Adaptive

Fixed node

Figure 2: The proposed ANFIS system.

where $x$ is the input with respect to node $i$ th and $A_{i}$ is a linguistic label. $M_{1}^{i}$ is the MF of $A_{i}$.

Layer 2 includes the fuzzy rule and a rule node which gets inputs and identifies firing strength of the rule. Each node is labeled as a circle node, $\amalg$. Each node output can be defined as

$$
w_{i}=\mu A_{i}(x) \times \mu A_{i}(y), \quad i=1,2,3, \ldots, n .
$$

Layer 3 is a normalized layer which is used to estimate a ratio of firing strength of a given rule to total of firing strengths of all rules. Every node is labeled as a circle node, $N$. In this layer, $\bar{w}$ is named for normalized firing strength of rules and defined as

$$
\bar{w}=\frac{w_{i}}{w_{1}+w_{2}+w_{3}, \ldots,+w_{n}}, \quad i=1,2,3, \ldots, n .
$$

Layer 4 is the defuzzification process, and the $i$ th node is labeled as square node by

$$
M_{1}^{i}=\bar{w}_{i} f_{i}(a x+b y, \ldots, c), \quad i=1,2,3, \ldots, n .
$$

Layer 5 is an overall output and sum of all signals, which is defined as

$$
M_{5}^{i}=\sum_{i} \bar{w}_{i} f_{i} \frac{\sum_{i} w_{i} f_{i}}{w_{i}} .
$$

In this article, the trapezoidal MFs are adopted for the ANFIS system as well.

2.5. Phase 5: Lightning Attachment Procedure Optimization Algorithm. LAPO is a new algorithm based on a physically lightning phenomena [59]. It is one of the most nontuned parameter algorithms. LAPO algorithm can solve a lot of different engineering problems, and it is superior to other metaheuristic algorithms [60]. Therefore, this study adopts the LAPO algorithm to expand its application capacity for the MOO design for the bridge amplification compliant mechanism. Readers can find details in literatures $[59,60]$. It consists of five substeps as follows.

\section{Step 1. Initialization}

The algorithm needs an initial population in a search space of design variables. Unlike previous studies, the present work evaluates and refines the search spaces in which a set of decision variables are defined based on statistical analysis. In the LAPO, some test points are assigned in the cloud and ground surface, which can be defined as

$$
x_{\text {testpoint }}^{i}=x_{\text {min }}^{i}+\left(x_{\max }^{i}-x_{\text {min }}^{i}\right) \times \operatorname{rand}[0,1],
$$

where $x_{\min }^{i}$ and $x_{\max }^{i}$ denote the upper and lower bounds of design variables. Rank is a randomly given parameter in range from zero to one. Fitness of the solution is defined as

$$
F_{\text {testpoint }}^{i}=\operatorname{obj}\left(x_{\text {testpoint }}^{i}\right) \text {. }
$$

Step 2. Next jump determination

The average value of the overall test points and the value of fitness of the points are computed as in equations (17) and (18), respectively:

$$
\begin{gathered}
x_{\text {average }}=\operatorname{mean}\left(x_{\text {testpoint }}\right), \\
f_{\text {average }}=\operatorname{obj}\left(x_{\text {average }}\right),
\end{gathered}
$$

where $x_{\text {average }}$ and $f_{\text {average }}$ denote the average value and value of fitness of the points.

If the electric field, fitness function, of potential point $h$ is greater than the average value of the test points, it is calculated as

$$
\begin{aligned}
x_{\text {testpoint_new }}^{i}= & x_{\text {testpoint }}^{i}+\operatorname{rand}[0,1] \times\left(x_{\text {average }}+\operatorname{rand}[0,1]\right. \\
& \left.\times\left(x_{\text {potential point }}^{h}\right)\right) .
\end{aligned}
$$

Otherwise, it is calculated as

$$
\begin{aligned}
x_{\text {testpoint_new }}^{i}= & x_{\text {testpoint }}^{i}-\operatorname{rand}[0,1] \times\left(x_{\text {average }}+\operatorname{rand}[0,1]\right. \\
& \left.\times\left(x_{\text {potential point }}^{h}\right)\right) .
\end{aligned}
$$

Step 3. Branch fading

If the fitness function of new test point is better than the previous point, the branch sustains; otherwise, the branch fades as

$$
\begin{cases}x_{\text {testpoint }}^{i}=x_{\text {testpoint_new }}^{i}, & f_{\text {testpoint_new }}^{i}<f_{\text {testpoint }}^{i}, \\ x_{\text {testpoint_new }}^{i}=x_{\text {testpoint }}^{\mathrm{i}}, & \text { otherwise. }\end{cases}
$$

This step is carried out for overall the test points so as to rest points moving down. 
Step 4. Upward leader movement

Upward leader movement calculates an exponent factor based on the charge of downward leader as

$$
S=1-\frac{\text { noi }}{\text { noi }_{\text {max }}} \times \exp \left(-\frac{\text { noi }}{\text { noi }_{\text {max }}}\right),
$$

where noi and noi $i_{\max }$ denote a number of iterations and maximum number of iterations, respectively. The upward leaders are defined for the next strategy of test point as

$$
x_{\text {testpoint_new }}=x_{\text {testpoint_new }}+\operatorname{rand}[0,1] \times S\left(x_{\min }-x_{\max }\right) \text {, }
$$

where $x_{\min }$ and $x_{\max }$ denote the best value and the worst solution of the population.

\section{Step 5. Final jump}

The process is ended when the upward leader meets the downward leader to each other. It is noted that the optimization process is ended if stop criterion is achieved. In addition, the maximum iteration is met, and the process is ended herein.

\section{Case Studies: MOO Design for Scott Russell Compliant Mechanism}

MOO design of the Scott Russell compliant mechanism is studied. This article considers three numerical examples, and the obtained results are to evaluate application's capability and effectiveness of the proposed hybrid computational method.

3.1. Structural Description and Problem Statement. Figure 3 describes a structural design of the Scott Russell compliant mechanism (SRCM). Bottom end of the mechanism is fixed by screws, and top end is output. The mechanism is a type of bridge amplifier, but four bridge legs are alternated by using four Scott Russell mechanisms. The purpose of alternative is to enhance stiffness of traditional bridge mechanism. Each Scott Russell mechanism includes four flexure hinges and rigid links, as shown in Figure 3. The output, end effector, is at the middle rigid link. Based on symmetry, the end effector can move along the $y$-axis by exciting two input loads from a piezoelectric actuator. Based on this design, the mechanism can amplify a large working stroke along the $y$-direction, but its natural frequency is decreased. Another problem is how to ensure an enough working strength, i.e., a long fatigue working life without plastic failure. In a such situation, this study proposes a new optimal design methodology to resolve a balance between displacement and frequency. The main parameters of SRCM are illustrated, as given in Figures 3 and 4. In this article, AL T73-7075 material is chosen for the mechanism. In this structure, some parameters are design variables and others are constant values.

Table 1 gives geometrical factors and material properties of the proposed mechanism. According to the designer's experiences and expert's knowledge in the field, spaces of design variables are determined based on a capacity of fabrication device.

The purpose of this study is to develop a new hybrid computational approach to deal with the MOO problem for compliant mechanisms. The SRCM is an application example. Numerical investigations are carried out to validate the proposed hybrid computational method. To address about the MOO problem for the SRCM, the design variables, objective functions, and constraints are firstly identified. According to the theory and investigations on compliant mechanisms [10, 61-64], geometry and locations of flexure hinges mainly contribute on the performances. As seen in Figures 3 and 4, the dimensional parameters are represented as a vector $\mathbf{X}=\left[\theta, L_{0}, L_{1}, L_{2}, L_{3}, L_{4}, L_{5}, L_{6}, D, T, R, H, L, W\right]^{T}$ in which the key design variables are affecting the performances, including $\theta, L_{1}, L_{2}, L_{3}, L_{4}$, and $D$. Regarding objective functions and constraints, the SRCM is expected to achieve a fast speed, a large working space, and a good strength. In order to reach a desired speed, the first natural frequency of the SRCM must be improved accordingly. Meanwhile, a large displacement of the SRCM can help toward a large working stroke. At last, a good strength can be gained if the resulting equivalent stress of SRCM is under the yield strength of material [10, 61-64]. In addition, based on the experiences in designing and analyzing kinematics of compliant mechanisms, the mentioned parameters $\left(\theta, L_{1}, L_{2}\right.$, $L_{3}, L_{4}$, and $D$ ) are very sensitive to the performances. They can be chosen properly to improve the performances. The formulation of the optimization problem of the SRCM is briefly stated as follows.

Find vector of design variable: $\mathbf{X}=\left[\theta, L_{1}, L_{2}, L_{3}, L_{4}, D\right]^{T}$

$$
\begin{gathered}
\text { Maximize } F_{1}(\mathbf{X}) \\
\text { Maximixe } F_{2}(\mathbf{X}) .
\end{gathered}
$$

Subject to constraints:

$$
F_{3}(\mathbf{X}) \leq \frac{\sigma_{a}}{S F}
$$

Initial space of design variables:

$$
\left\{\begin{array}{l}
12.5^{\circ} \leq \theta \leq 16.5^{\circ} \\
4.9 \mathrm{~mm} \leq L_{1} \leq 7.7 \mathrm{~mm} \\
14.5 \mathrm{~mm} \leq L_{2} \leq 18.7 \mathrm{~mm} \\
8.5 \mathrm{~mm} \leq L_{3} \leq 11.825 \mathrm{~mm} \\
14 \mathrm{~mm} \leq L_{4} \leq 18.7 \mathrm{~mm} \\
2.25 \mathrm{~mm} \leq D \leq 3.5 \mathrm{~mm}
\end{array}\right.
$$

where $F_{1}(\mathbf{X}), F_{2}(\mathbf{X})$, and $F_{3}(\mathbf{X})$ denote the frequency, displacement, and equivalent stress, respectively. $\sigma_{a}$ is the yield stress of proposed Al T73-7075. Specifically, $F_{1}(\mathbf{X})$ and $F_{2}(\mathbf{X})$ are two objective functions, while $F_{3}(\mathbf{X})$ is regarded as the constraint. SF is the safety factor that is chosen as 1.5 .

3.2. Numerical Simulation. A 3D FEM model is created, and numerical experiments are formulated via the CCD. $\mathrm{Nu}-$ merical data are then collected by implementing FEA simulations. The boundary conditions and loads are given 


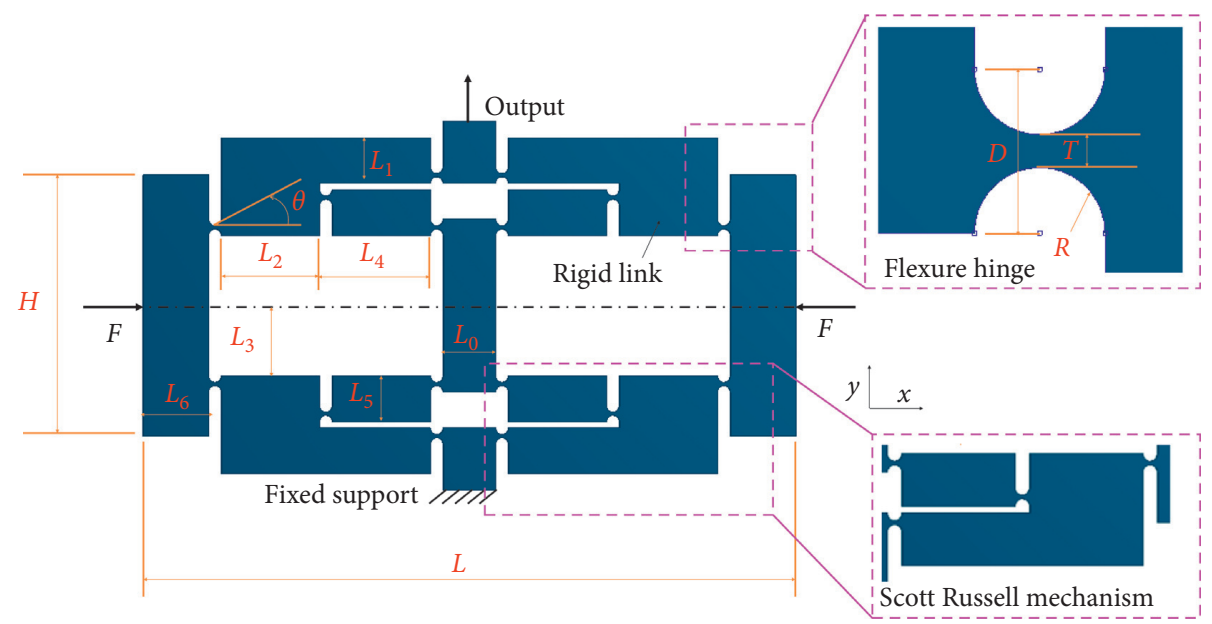

FIGURE 3: Schematics of the Scott Russell compliant mechanism.

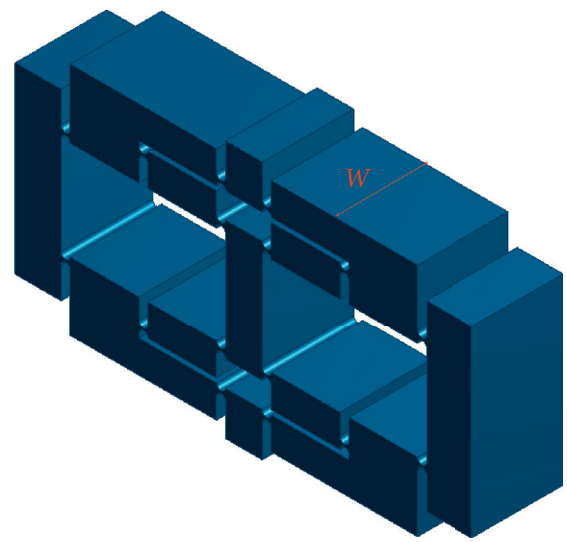

Figure 4: 3D model of the Scott Russell compliant mechanism (unit: mm).

TABLE 1: Design parameters and material properties of the SRCM mechanism.

\begin{tabular}{lcc}
\hline Parameter & Symbol & Value \\
\hline Incline angle & $\theta$ & $12.5^{\circ} \leq \theta \leq 16.5^{\circ}$ \\
Width of rigid link 1 & $L_{1}$ & $4.9 \mathrm{~mm} \leq L_{1} \leq 7.7 \mathrm{~mm}$ \\
Length of segment 1 & $L_{2}$ & $14.5 \mathrm{~mm} \leq L_{2} \leq 18.7 \mathrm{~mm}$ \\
Distance from actuator to rigid link & $L_{3}$ & $8.5 \mathrm{~mm} \leq L_{3} \leq 11.825 \mathrm{~mm}$ \\
Length of segment 2 & $L_{4}$ & $14 \mathrm{~mm} \leq L_{4} \leq 18.7 \mathrm{~mm}$ \\
Distance between circle's centers & $D$ & $2.25 \mathrm{~mm} \leq D \leq 3.5 \mathrm{~mm}$ \\
Width of shuttle link & $L_{0}$ & $8 \mathrm{~mm}$ \\
Width of rigid link 2 & $L_{5}$ & $7 \mathrm{~mm}$ \\
Width of input link & $L_{6}$ & $10 \mathrm{~mm}$ \\
Radius of flexure hinge & $R$ & $1 \mathrm{~mm}$ \\
Thickness of flexure hinge & $T$ & $(\mathrm{D}-\mathrm{R}) \mathrm{mm}$ \\
Width of the mechanism & $W$ & $10 \mathrm{~mm}$ \\
Height of the mechanism & $H$ & $40 \mathrm{~mm}$ \\
Length of the mechanism & $L$ & $100 \mathrm{~mm}$ \\
Total size of the mechanism & $S$ & $100 * 40 * 10 \mathrm{~mm} \mathrm{~m}^{3}$ \\
Mechanical properties of Al T73-7075 & & $2810 \mathrm{~kg} / \mathrm{m}^{3}$ \\
Density & & $71700 \mathrm{MPa}$ \\
Young's modulus & & $503 \mathrm{MPa}$ \\
Yield strength & & 0.33 \\
Poisson's ratio & &
\end{tabular}


from Figure 3. A force, $F$, of $70 \mathrm{~N}$ is applied toward an end of inputs, and the output response is measured. Automatic technique is utilized for meshing. Meshing of flexure hinges is refined again in order to achieve accurate analysis, as shown in Figure 5. The meshing results give a number of elements of 1544 and a number of nodes of 9897 . Skewness criteria, metric performance, are used to evaluate the quality of meshing. Its value is in the range from zero to one. The results found that the average value of skewness is approximately 0.3745 , as given in Figure 6 . On the contrary, this value guarantees the quality of meshing is a relatively good result.

\section{Results and Discussion}

4.1. Sensitivity Investigation and Refinement of Design Variables. The CCD is utilized to build the numerical matrix by using space of all initial design variables. And then, the most critical important parameters and suppress nonsignificant parameters are identified. Secondly, this analysis refines space of design variables prior to implement the MOO problem of proposed mechanism. In this article, six factors are divided into three levels, as given in Table 2. Each numerical experiment retrieves two quality specifications and one constraint, including natural frequency $\left(F_{1}(\mathbf{X})-\mathrm{Hz}\right)$, displacement $\left(F_{2}(\mathbf{X})-\mathrm{mm}\right)$, and equivalent stress $\left(F_{3}(\mathbf{X})-\mathrm{MPa}\right)$. Forty-five experiments are generated, and the numerical results are given, as in Table 3.

As mentioned above, this article considers displacement, frequency, and stress for MOO design of the Scott Russell compliant mechanism. Geometrical parameters directly affecting those specifications are identified and may be suppressed for further optimization process. Sensitivity investigation of design variables with respect to the three specifications is analyzed, individually. In this study, analysis of variance and Taguchi approach are used and implemented by using Minitab software 18.

Case 1, considering the displacement, ANOVA is utilized to analysis of sensitivity at $95 \%$ confidence interval. The result of ANOVA in Table 4 found that the contribution of parameters $\theta$ (the-ta), $L_{1}$, and $L_{2}$ on this quality response is about $0.03 \%, 0.02 \%$, and $0.01 \%$, respectively. These contributions are too small compared to remaining parameters. It means that the contributions of $\theta, L_{1}$, and $L_{2}$ can be ignored in further modeling and optimization process. In addition, the Taguchi method with the larger-the-better type is used for the displacement, as shown in Figure 7. The results also found that factors $\theta, L_{1}$, and $L_{2}$ are also two nonsignificant factors because the displacement is a little change when those parameters are varied. Meanwhile, other parameters are very sensitive to the displacement which are taken as key variables for case study 1 .

Considering the frequency, the ANOVA results in Table 5 reveal that parameters $L_{3}$ and $L_{4}$ have a lowest contribution on the displacement with respect to $0.09 \%$ and $0.22 \%$, respectively. As a result, these two factors are nonsignificant variables that can be neglected in modeling and optimization process for case study 2 .

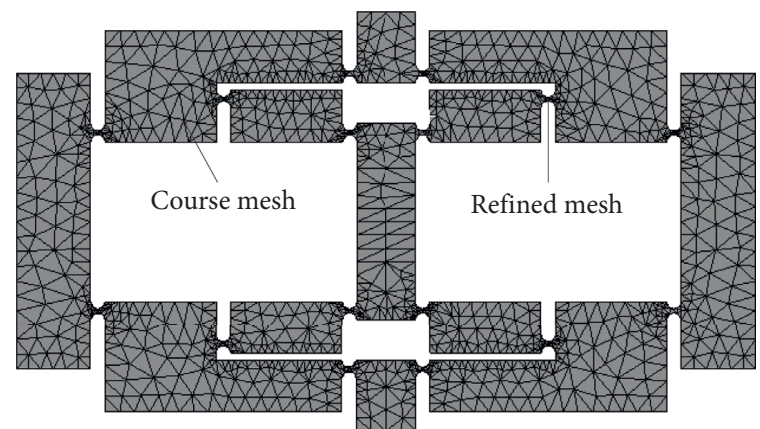

FIgURE 5: Meshing model of Scott Russell compliant mechanism.

Figure 8 describes the sensitivity of full variables on the frequency via using the Taguchi method with the larger-thebetter type. It also notes that the parameters $L_{3}$ and $L_{4}$ have a very small influence on this response compared to other parameters. On the contrary, if these parameters are varied, the frequency is somehow changed. Meanwhile, a change in the other parameters has a sharp change.

Case 3 considers the equivalent stress, and the ANOVA results in Table 6 indicate that three parameters $\theta, L_{2}$, and $L_{4}$ have the lowest contribution on the stress with $0 \%$ contribution. These three factors are nonsignificant and can be suppressed in further modeling and the MOO process. A smaller-the-better type is utilized for the stress. The results of the Taguchi analysis show that three parameters also have a very small contribution on the stress response, as shown in Figure 9.

\subsection{Optimization Implementation}

4.2.1. Selection of Membership Functions. Each real value of physical response is transformed into linguistic variables which are assigned for the fuzzy reasoning inference process. The linguistic variables are determined based on expert's knowledge and designer's institution. Table 7 gives the linguistic variables, including tiny, very small, small, smallmedium, medium, medium-large, large, very large, and huge.

In this article, two inputs of FIS structure consist of desirability of frequency and desirability of displacement. The MFs for desirability of frequency are divided into three levels such as small, medium, and large, as illustrated in Figure 10(a). Meanwhile, the MFs of the desirability of displacement are separated into seven levels, including tiny, very small, small-medium, medium, medium-large, large, very large, and huge, as depicted in Figure 10(b). At last, the MFs of the output MPCI also include seven levels, as shown in Figure 11. All the MFs are defined by trapezoidal shape because this is a popular MF type for both the FIS and ANFIS models.

The results of sensitivity analysis are used to decrease space of design variables. Through this analysis, computational time is lowered and reliable solution is increased. Particularly, some parameters may be redundant, while others are critically important factors. Based on the sensitivity results, initial design variables are eliminated. From 


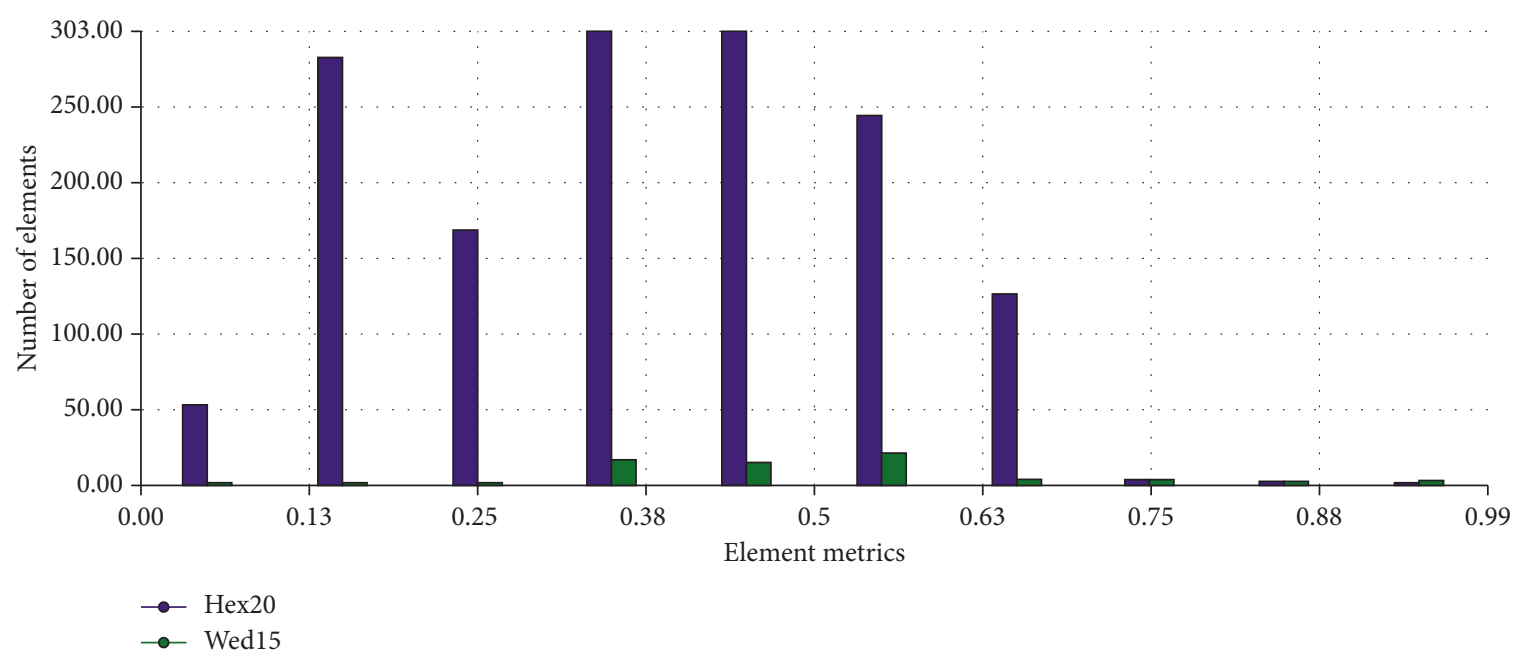

FIgURE 6: Quality distribution of meshing elements by skewness criteria.

TABLE 2: Level of design variables.

\begin{tabular}{lcccc}
\hline Symbol & Value & Level 1 & Level 2 & Level 3 \\
\hline$\theta$ & $12.5^{\circ} \leq \theta \leq 16.5^{\circ}$ & 12.5 & 14.5 & 16.5 \\
$L_{1}$ & $4.9 \mathrm{~mm} \leq L_{1} \leq 7.7 \mathrm{~mm}$ & 4.9 & 6.3 & 7.7 \\
$L_{2}$ & $14.5 \mathrm{~mm} \leq L_{2} \leq 18.7 \mathrm{~mm}$ & 14.5 & 16.6 & 18.7 \\
$L_{3}$ & $8.5 \mathrm{~mm} \leq L_{3} \leq 11.825 \mathrm{~mm}$ & 8.5 & 10.1625 & 11.825 \\
$L_{4}$ & $14 \mathrm{~mm} \leq L_{4} \leq 18.7 \mathrm{~mm}$ & 14 & 16.35 & 18.7 \\
$D$ & $2.25 \mathrm{~mm} \leq D \leq 3.5 \mathrm{~mm}$ & 2.25 & 2.825 & 3.5 \\
\hline
\end{tabular}

that, three following numerical examples are considered to evaluate the performance effectiveness of proposed computational methodology.

If full initial space is used, it may take a long time to search for optimum solutions. Therefore, this study limits design space and following case studies are separated to investigate and evaluate the efficiency of the proposed hybrid approach.

4.2.2. Case Study 1. By using the results of sensitivity analysis in Table 4 and Figure 7, some nonsignificant factors are suppressed since their influences are very small on the displacement. Real influencing factors with large contributions are taken in account as key design variables. Case study 1 takes two objective functions to be optimized simultaneously with the spaces of design variables being relatively reduced. In order to solve the MOO problem, the desirability of displacement and the desirability of frequency are transformed into a single combined objective function, which is called as the MPCI of the FIS system. Subsequently, the MPCI is maximized by using the proposed hybrid approach. The optimization problem of case study 1 is stated as follows.

Find vector of design variable: $\mathbf{X}=\left[D, L_{3}, L_{4}\right]^{\mathrm{T}}$ :

$$
\operatorname{Maximize} \operatorname{MPCI}(\mathbf{X})_{\text {case study } 1}
$$

s.t.

$$
\left\{\begin{array}{l}
F_{3}(\mathbf{X}) \leq \frac{\sigma_{a}}{S F} \\
2.25 \mathrm{~mm} \leq D \leq 3.5 \mathrm{~mm} \\
8.5 \mathrm{~mm} \leq L_{3} \leq 11.825 \mathrm{~mm} \\
14 \mathrm{~mm} \leq L_{4} \leq 18.7 \mathrm{~mm}
\end{array}\right.
$$

Case study 1 evaluates three design variables $\left(D, L_{2}\right.$, and $L_{1}$ ) and two objective functions and one constraint. Such design variables and both responses are set as parametric variables in the FE model. Based on the number of design variables and their levels, CCD is used again to build 15 experiments. The results of frequency, displacement, and equivalent stress are collected, simultaneously.

Next, desirability of frequency and desirability of displacement are calculated, as given in Table 8. Real values of two responses have different units, and it is a main cause resulting in unprecise solutions. Therefore, desirability function approach is proposed to overcome this limitation because desirability has no unit and its value is from zero to one. The results found all stress values are satisfied in terms of allowable stress of material.

In order to conduct the MOO problem for case study 1 , the MFs for desirability of frequency include three levels and the desirability of displacement is divided into seven levels, while the MFs of fuzzy MPCI output are separated into seven levels, as given in Table 9. Subsequently, matrix of fuzzy rules is built in this table.

In this study, center of gravity method is employed for defuzzification and Mamdani method is utilized for fuzzy operation. The FIS is implemented in Matlab R2015a. Figure 12 illustrates a relation of the fuzzy MPCI with the 
TABLE 3: Initially numerical results: frequency, displacement, and equivalent stress.

\begin{tabular}{|c|c|c|c|c|c|c|c|c|c|}
\hline \multirow{2}{*}{ No. } & \multicolumn{6}{|c|}{ Design variables } & \multirow{2}{*}{$\begin{array}{l}\text { Frequency } \\
F_{1}(\mathrm{X})(\mathrm{Hz})\end{array}$} & \multirow{2}{*}{$\begin{array}{c}\text { Displacement } \\
F_{2}(\mathrm{X})(\mathrm{mm})\end{array}$} & \multirow{2}{*}{$\begin{array}{c}\text { Stress } \\
F_{3}(\mathrm{X})(\mathrm{MPa})\end{array}$} \\
\hline & $\theta$ (degree) & $L_{1}(\mathrm{~mm})$ & $L_{2}(\mathrm{~mm})$ & $L_{3}(\mathrm{~mm})$ & $L_{4}(\mathrm{~mm})$ & $D(\mathrm{~mm})$ & & & \\
\hline 1 & 14.5 & 6.3 & 16.6 & 10.1625 & 16.35 & 2.875 & 144.8765116 & 0.0131662 & 20.2101534 \\
\hline 2 & 12.5 & 6.3 & 16.6 & 10.1625 & 16.35 & 2.875 & 145.6511486 & 0.0100512 & 17.3713011 \\
\hline 3 & 16.5 & 6.3 & 16.6 & 10.1625 & 16.35 & 2.875 & 142.7061870 & 0.0124471 & 21.6504283 \\
\hline 4 & 14.5 & 4.9 & 16.6 & 10.1625 & 16.35 & 2.875 & 144.5375979 & 0.0111032 & 19.3343769 \\
\hline 5 & 14.5 & 7.7 & 16.6 & 10.1625 & 16.35 & 2.875 & 147.0998526 & 0.0101186 & 22.7858141 \\
\hline 6 & 14.5 & 6.3 & 14.5 & 10.1625 & 16.35 & 2.875 & 153.7702955 & 0.0089541 & 14.8769691 \\
\hline 7 & 14.5 & 6.3 & 18.7 & 10.1625 & 16.35 & 2.875 & 138.4140708 & 0.0104084 & 18.2311317 \\
\hline 8 & 14.5 & 6.3 & 16.6 & 10.1625 & 16.35 & 2.25 & 29.1033323 & 0.2783916 & 413.3649425 \\
\hline 9 & 14.5 & 6.3 & 16.6 & 10.1625 & 16.35 & 3.5 & 247.7177837 & 0.0042301 & 9.1823943 \\
\hline 10 & 14.5 & 6.3 & 16.6 & 8.5 & 16.35 & 2.875 & 151.3503923 & 0.0132612 & 20.5864700 \\
\hline 11 & 14.5 & 6.3 & 16.6 & 11.825 & 16.35 & 2.875 & 139.8224967 & 0.0132187 & 19.7278662 \\
\hline 12 & 14.5 & 6.3 & 16.6 & 10.1625 & 14 & 2.875 & 158.4167103 & 0.0106565 & 18.8481276 \\
\hline 13 & 14.5 & 6.3 & 16.6 & 10.1625 & 18.7 & 2.875 & 137.7014871 & 0.0139512 & 19.6035371 \\
\hline 14 & 12.5 & 4.9 & 14.5 & 8.5 & 14 & 2.25 & 35.2827371 & 0.0126286 & 41.9016251 \\
\hline 15 & 16.5 & 4.9 & 14.5 & 8.5 & 18.7 & 2.25 & 29.7282702 & 0.0319123 & 68.4134201 \\
\hline 16 & 12.5 & 7.7 & 14.5 & 8.5 & 18.7 & 2.25 & 30.3150364 & 0.0440975 & 83.1659146 \\
\hline 17 & 16.5 & 7.7 & 14.5 & 8.5 & 14 & 2.25 & 35.2125256 & 0.0541169 & 118.3677978 \\
\hline 18 & 12.5 & 4.9 & 18.7 & 8.5 & 18.7 & 2.25 & 26.5880362 & 0.0605043 & 110.0556179 \\
\hline 19 & 16.5 & 4.9 & 18.7 & 8.5 & 14 & 2.25 & 30.2587478 & 0.0314902 & 81.1699723 \\
\hline 20 & 12.5 & 7.7 & 18.7 & 8.5 & 14 & 2.25 & 31.1153254 & 0.0262748 & 63.8299904 \\
\hline 21 & 16.5 & 7.7 & 18.7 & 8.5 & 18.7 & 2.25 & 661.0920453 & 0.0000156 & 8.3148176 \\
\hline 22 & 12.5 & 4.9 & 14.5 & 8.5 & 18.7 & 3.5 & 236.4448793 & 0.0020741 & 7.3108765 \\
\hline 23 & 16.5 & 4.9 & 14.5 & 8.5 & 14 & 3.5 & 284.3688928 & 0.0034154 & 11.4796060 \\
\hline 24 & 12.5 & 7.7 & 14.5 & 8.5 & 14 & 3.5 & 296.0385722 & 0.0028695 & 10.0679057 \\
\hline 25 & 16.5 & 7.7 & 14.5 & 8.5 & 18.7 & 3.5 & 722.6186705 & 0.0000161 & 2.3844190 \\
\hline 26 & 12.5 & 4.9 & 18.7 & 8.5 & 14 & 3.5 & 249.2833206 & 0.0037318 & 9.8955675 \\
\hline 27 & 16.5 & 4.9 & 18.7 & 8.5 & 18.7 & 3.5 & 216.1175651 & 0.0056673 & 10.8787519 \\
\hline 28 & 12.5 & 7.7 & 18.7 & 8.5 & 18.7 & 3.5 & 660.5761253 & 0.0000153 & 2.4110693 \\
\hline 29 & 16.5 & 7.7 & 18.7 & 8.5 & 14 & 3.5 & 723.9722661 & 0.0000184 & 2.3225403 \\
\hline 30 & 12.5 & 4.9 & 14.5 & 11.825 & 18.7 & 2.25 & 26.7029456 & 0.0095992 & 28.5990240 \\
\hline 31 & 16.5 & 4.9 & 14.5 & 11.825 & 14 & 2.25 & 32.3612774 & 0.0773006 & 175.6411982 \\
\hline 32 & 12.5 & 7.7 & 14.5 & 11.825 & 14 & 2.25 & 33.5994617 & 0.0998207 & 203.6469876 \\
\hline 33 & 16.5 & 7.7 & 14.5 & 11.825 & 18.7 & 2.25 & 26.4888400 & 0.2497774 & 343.3155557 \\
\hline 34 & 12.5 & 4.9 & 18.7 & 11.825 & 14 & 2.25 & 28.9826859 & 0.2040589 & 377.6240900 \\
\hline 35 & 16.5 & 4.9 & 18.7 & 11.825 & 18.7 & 2.25 & 22.7266747 & 0.1692049 & 257.2457599 \\
\hline 36 & 12.5 & 7.7 & 18.7 & 11.825 & 18.7 & 2.25 & 23.4218271 & 0.1117737 & 173.0523059 \\
\hline 37 & 16.5 & 7.7 & 18.7 & 11.825 & 14 & 2.25 & 671.0395540 & 0.0000197 & 8.0316806 \\
\hline 38 & 12.5 & 4.9 & 14.5 & 11.825 & 14 & 3.5 & 254.0503542 & 0.0020926 & 8.4557853 \\
\hline 39 & 16.5 & 4.9 & 14.5 & 11.825 & 18.7 & 3.5 & 222.0867129 & 0.0038711 & 11.9575653 \\
\hline 40 & 12.5 & 7.7 & 14.5 & 11.825 & 18.7 & 3.5 & 226.4134777 & 0.0034449 & 8.6649529 \\
\hline 41 & 16.5 & 7.7 & 14.5 & 11.825 & 14 & 3.5 & 728.8362254 & 0.0000215 & 2.0182197 \\
\hline 42 & 12.5 & 4.9 & 18.7 & 11.825 & 18.7 & 3.5 & 200.9526441 & 0.0042152 & 10.8241011 \\
\hline 43 & 16.5 & 4.9 & 18.7 & 11.825 & 14 & 3.5 & 237.2856932 & 0.0032948 & 10.7328140 \\
\hline 44 & 12.5 & 7.7 & 18.7 & 11.825 & 14 & 3.5 & 668.7600073 & 0.0000200 & 1.9910749 \\
\hline 45 & 16.5 & 7.7 & 18.7 & 11.825 & 18.7 & 3.5 & 610.9395221 & 0.0000201 & 2.3080380 \\
\hline
\end{tabular}

TABle 4: ANOVA results for the displacement.

\begin{tabular}{lccccc}
\hline Source & DF & Seq. SS & Adj. SS & Adj. MS & Contribution (\%) \\
\hline Model & 6 & 0.073316 & 0.073316 & 0.012219 & 38.01 \\
Linear & 6 & 0.073316 & 0.073316 & 0.012219 & 38.01 \\
$\theta$ & 1 & 0.000060 & 0.000060 & 0.000060 & 0.03 \\
$L_{1}$ & 1 & 0.000033 & 0.000033 & 0.000033 & 0.02 \\
$L_{2}$ & 1 & 0.000018 & 0.000018 & 0.012798 & 0.01 \\
$L_{3}$ & 1 & 0.012798 & 0.012798 & 0.000935 & 0.64 \\
$L_{4}$ & 1 & 0.000935 & 0.000935 & 0.059470 & 30.83 \\
$D$ & 1 & 0.059470 & 0.059470 & 0.003146 & 61.99 \\
Error & 38 & 0.119565 & 0.119565 & & 100.00 \\
Total & 44 & 0.192880 & & \\
\hline
\end{tabular}




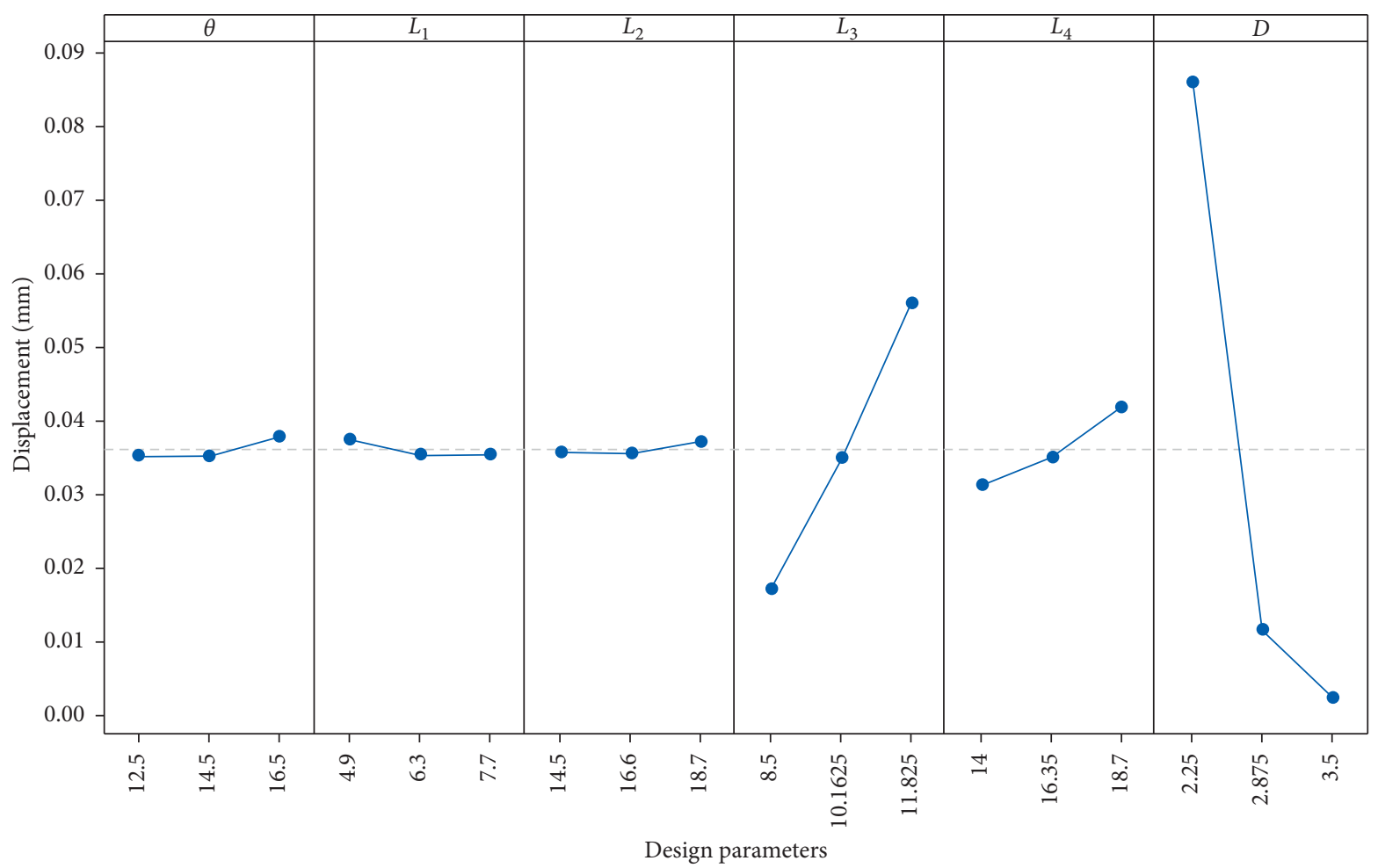

FIGURE 7: Effect plot of design variables on the displacement.

TABLE 5: ANOVA results for the frequency.

\begin{tabular}{lccccc}
\hline Source & DF & Seq. SS & Adj. SS & Adj. MS & Contribution (\%) \\
\hline Model & 6 & 1465058 & 1465058 & 244176 & 62.89 \\
Linear & 6 & 1465058 & 1465058 & 244176 & 62.89 \\
$\Theta$ & 1 & 145431 & 145431 & 145431 & 6.24 \\
$L_{1}$ & 1 & 475254 & 475254 & 475254 & 20.40 \\
$L_{2}$ & 1 & 98197 & 98197 & 98197 & 4.22 \\
$L_{3}$ & 1 & 2079 & 2079 & 2079 & 0.09 \\
$L_{4}$ & 1 & 5138 & 5138 & 5138 & 0.22 \\
$D$ & 1 & 738958 & 738958 & 738958 & 31.72 \\
Error & 38 & 864635 & 864635 & 22754 & 37.11 \\
Total & 44 & 2329692 & & & 100.00 \\
\hline
\end{tabular}

desirability of displacement and desirability of frequency. The value of inputs and outputs of the FIS is in range from zero to one. In this study, the weight of each rule is assumed to be unity.

Based on 27 fuzzy rules in Table 9, the output of FIS system is computed, as shown in Figure 13.

The results of MPCI output are determined with respect to each value of desirability of frequency and desirability of displacement, as given in Table 10 .

By taking the values of design variables in Table 8 and the MPCI value in Table 10, a proper ANFIS model is developed for modeling the MPCI. Modeling is coded in Matlab. The results of ANFIS parameters are given in Table 11. In this study, $75 \%$ of data and the remaining $25 \%$ of data are utilized for the training and testing, respectively.

In order to evaluate the built ANFIS model, some performances metrics are employed, such as mean absolute percentage error (MAPE), root mean square error (RMSE), and correlation coefficient $\left(R^{2}\right)[18,65]$. Mathematical equations of MAPE, RMSE, and $R^{2}$ are described by

$$
\begin{aligned}
\text { MAPE } & =\frac{100 \%}{n} \sum_{i=1}^{n}\left|\frac{y_{i}-\hat{y}_{i}}{y_{i}}\right|, \\
\text { RMSE } & =\sqrt{\frac{1}{n} \sum_{i=1}^{n}\left(y_{i}-\hat{y}_{i}\right)^{2},} \\
R^{2} & =1-\frac{\sum_{i=1}^{n}\left(y_{i}-\hat{y}_{i}\right)^{2}}{\sum_{i=1}^{n}\left(y_{i}-\bar{y}_{i}\right)^{2}},
\end{aligned}
$$

where $y_{i}$ is the $i$ th of the measured result, $\widehat{y}_{i}$ is the $i$ th of the predicted result, $\bar{y}$ is the mean value of measured results, and $n$ is the number of observations.

As the discussion in Section 3.1, a high frequency, a large displacement, and a minimal stress are desired simultaneously. According to the fuzzy logic theory [30], the largest value of the MPCI is expected to achieve the optimal solution. In other words, the MPCI must be maximized so as to achieve a global optimal solution for the SRCM. The results found that the MAPE and RMSE are close to zero, while $R^{2}$ reaches one. It means that the built ANFIS model is relatively good. In order to evaluate the effectiveness and robustness of the proposed hybrid approach, the optimal results are compared with those obtained from a traditional combination of the Taguchi method and fuzzy logic (TMFL), and the optimal parameters from the TMFL are determined at 


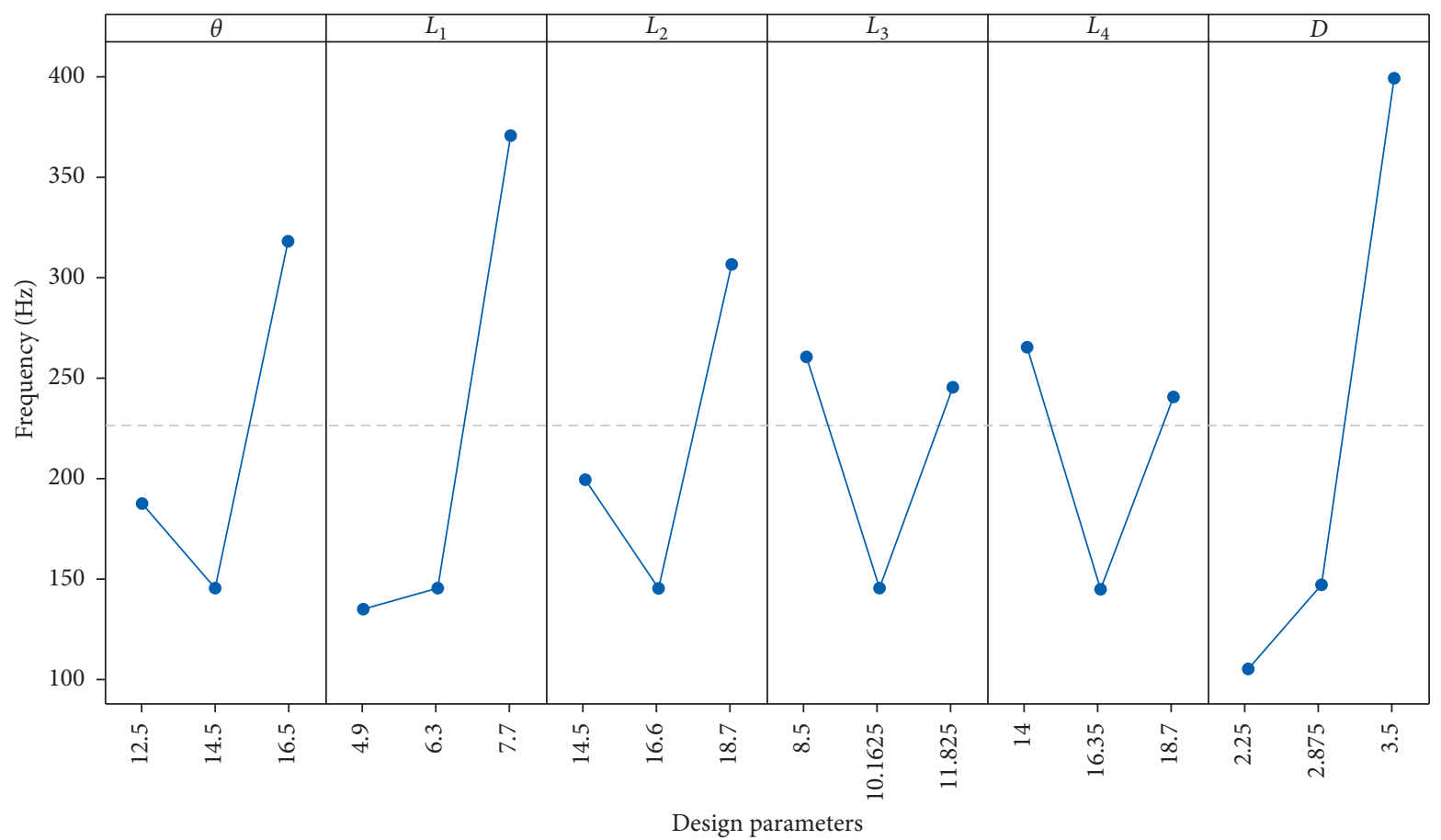

FIgURE 8: Effect plot of design variables on the frequency.

TABLE 6: ANOVA results for the equivalent stress.

\begin{tabular}{|c|c|c|c|c|c|}
\hline Source & DF & Seq. SS & Adj. SS & Adj. MS & Contribution (\%) \\
\hline Model & 6 & 204005 & 204005 & 34001 & 43.37 \\
\hline Linear & 6 & 204005 & 204005 & 34001 & 43.37 \\
\hline$\Theta$ & 1 & 15 & 15 & 15 & 0.00 \\
\hline$L_{1}$ & 1 & 1005 & 1005 & 1005 & 0.21 \\
\hline$L_{2}$ & 1 & 2 & 2 & 2 & 0.00 \\
\hline$L_{3}$ & 1 & 28901 & 28901 & 28901 & 6.14 \\
\hline$L_{4}$ & 1 & 0 & 0 & 0 & 0.00 \\
\hline$D$ & 1 & 174082 & 174082 & 174082 & 37.01 \\
\hline Error & 38 & 266343 & 266343 & 7009 & 56.63 \\
\hline Total & 44 & 470348 & & & 100.00 \\
\hline
\end{tabular}

$D=2.25 \mathrm{~mm}, L_{3}=8.5 \mathrm{~mm}$, and $L_{4}=18.7 \mathrm{~mm}$, as given in Table 12. The optimal results of TMFL find that the frequency and displacement are approximately $24.4574 \mathrm{~Hz}$ and $0.1691 \mathrm{~mm}$ with a small equivalent stress of $251 \mathrm{MPa}$, respectively. It also ensures a high safety factor. However, these optimal values are found at discrete points according to theory of the Taguchi approach. Such points can lead to local optimum solutions. To overcome this limitation, LAPO algorithm is used to search a global optimum solution. Based on the established ANFIS modeling, a pseudoobjective function of MPCI is well established. And then, a LAPO programming is implemented in Matlab R2019b, and the results of the proposed approach found that the optimal design parameters are at $D=2.30 \mathrm{~mm}, L_{3}=8.5 \mathrm{~mm}$, and $L_{4}=18.7 \mathrm{~mm}$. By using proposed methodology, the optimal solutions find the frequency and displacement are about $26.592 \mathrm{~Hz}$ and $0.1539 \mathrm{~mm}$, respectively. The equivalent stress is also lower than the yield strength of $\mathrm{Al}$ material. It permits a good enough working condition with a safety factor of
1.98. Moreover, the MPCI predicted from the TMFL is smaller than that predicted from the proposed hybrid methodology. According to a larger-the-better value is best for the MPCI, the proposed approach is efficient, robust, and better than the TMFL. The optimal results are satisfied with initial requirements.

4.2.3. Case Study 2. Based on the results of sensitivity analysis in Table 5 and Figure 8, some unimportant factors are neglected in modeling and optimization problem. The factors with actual contributions are considered as key design variables. The space of design parameters is decreased, accordingly. Similarly, case study 2 also maximizes $F_{1}(\mathbf{X})$ and maximizes $F_{2}(\mathbf{X})$, simultaneously. Two objective functions are transferred into desirability values and then transformed to the MPCI value. The optimization problem is briefly expressed as below.

Find design variable $\mathbf{X}=\left[\theta, L_{1}, L_{2}, D\right]^{T}$ : 


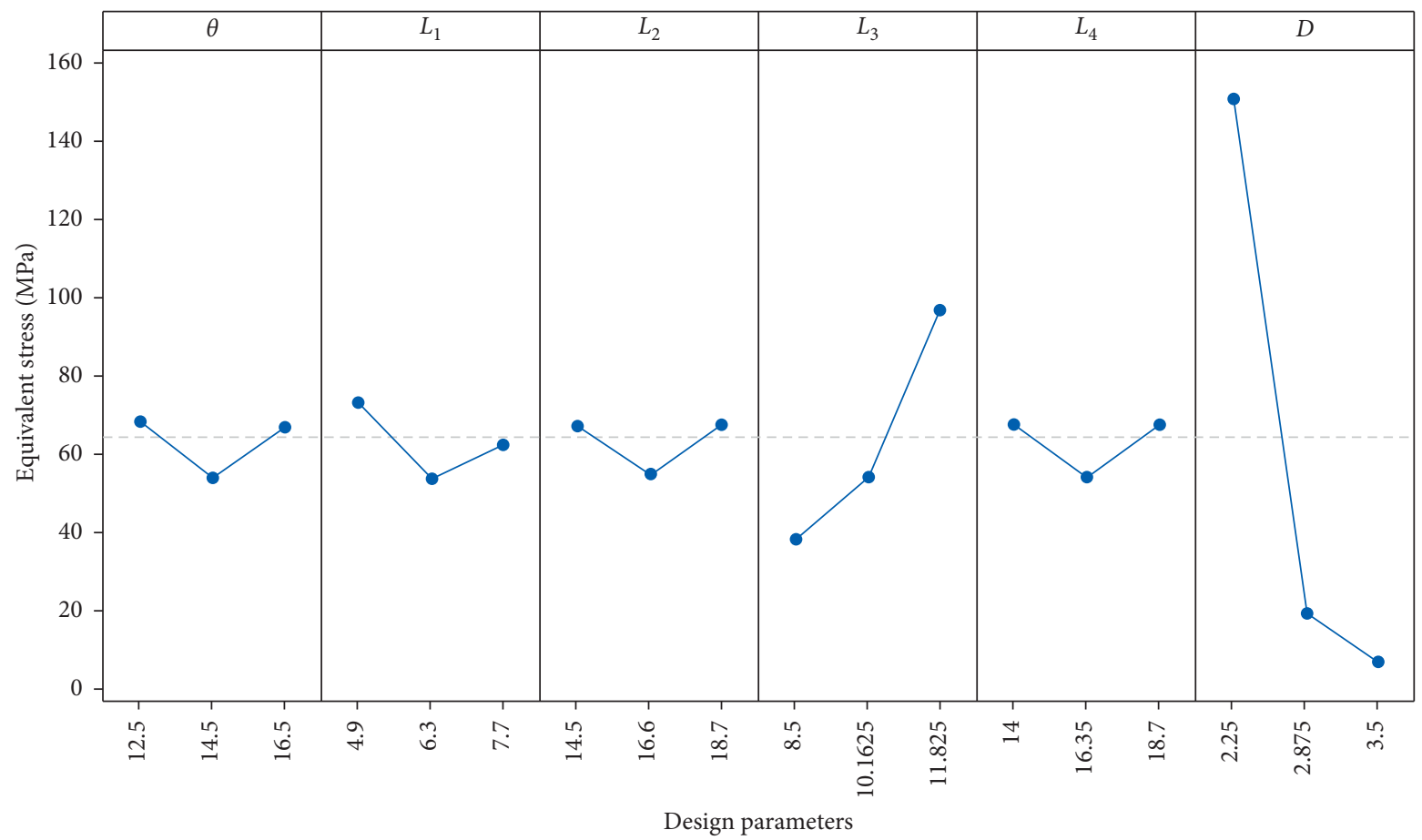

Figure 9: Effect plot of design variables on the stress.

TABLE 7: Linguistic variables for the fuzzy reasoning process.

\begin{tabular}{lccccccccc}
\hline Symbol & T & VS & S & SM & M & ML & L & VL & H \\
\hline Linguistic variables & Tiny & Very small & Small & Small-medium & Medium & Medium-large & Large & Very large & Huge \\
\hline
\end{tabular}

$$
\operatorname{Maximize} \operatorname{MPCI}(\mathbf{X})_{\text {case study } 2}
$$

s.t.

$$
\left\{\begin{array}{l}
F_{3}(\mathbf{X}) \leq \frac{\sigma_{a}}{S F}, \\
12.5^{\circ} \leq \theta \leq 16.5^{\circ}, \\
4.9 \mathrm{~mm} \leq L_{1} \leq 7.7 \mathrm{~mm}, \\
14.5 \mathrm{~mm} \leq L_{2} \leq 18.7 \mathrm{~mm}, \\
2.25 \mathrm{~mm} \leq D \leq 3.5 \mathrm{~mm} .
\end{array}\right.
$$

Case study 2 considers two design variables and two objective functions and three constraints. CCD is also used to build 25 numerical experiments. The results of frequency, displacement, and equivalent stress are collected by simulations. And then, desirability of displacement and desirability of frequency are calculated, as given in Table 13. The resulting stress values are under the allowable stress of Al T73-7075.

Next, the MFs for desirability of frequency also are divided into three levels, and the desirability of displacement is seven levels, while the MFs of fuzzy MPCI output are separated into seven levels, as given in Table 9. Subsequently, matrix of fuzzy rules is built in Table 14 .
The results of MPCI output are calculated corresponding to the desirability two responses, as given in Table 15.

By taking the values of design variables in Table 13 and the MPCI value of Table 15, ANFIS model is formed for modeling the MPCI. The ANFIS parameters for case study 2 are developed, as given in Table 16. The predicting accuracy of the ANFIS model is well evaluated through equations (29) and (31) before conducting the MOO problem for the SRCM.

By using the TMFL, the optimal parameters are determined at $\theta=16.5^{\circ}, L_{1}=7.7 \mathrm{~mm}, L_{2}=18.7 \mathrm{~mm}$, and $D=2.25 \mathrm{~mm}$, as given in Table 17. Based on the TMFL, the optimal frequency and displacement are found at $28.94823 \mathrm{~Hz}$ and $0.1527 \mathrm{~mm}$, respectively. Subsequently, LAPO algorithm is used to search a global optimum value. The results of the proposed hybrid approach determined that the optimal design parameters are $\theta=16.5^{\circ}, L_{1}=8.0 \mathrm{~mm}$, $L_{2}=14.5 \mathrm{~mm}$, and $D=2.25 \mathrm{~mm}$. Using the proposed methodology, the optimal results found that the frequency and displacement are about $651 \mathrm{~Hz}$ and $0.1981 \mathrm{~mm}$, respectively. Finally, the predicted MPCI from the proposed approach is greater than that predicted from the TMFL. It means that the estimated solution from the proposed methodology is robust and better than that from the TMFL. Moreover, it finds that the equivalent stress is under the allowable stress of $\mathrm{Al} \mathrm{T73-7075.} \mathrm{The} \mathrm{optimal} \mathrm{results} \mathrm{are}$ satisfied with design constraints. 


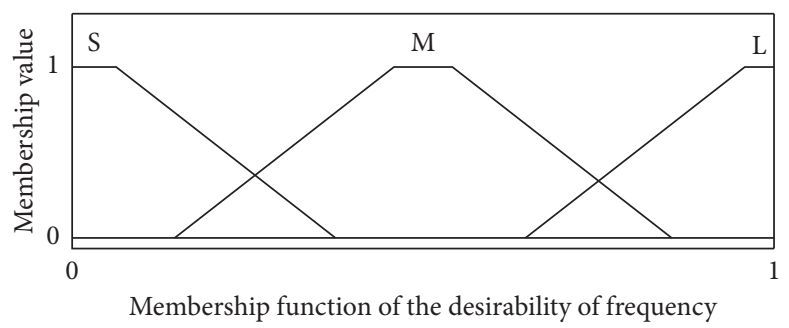

(a)

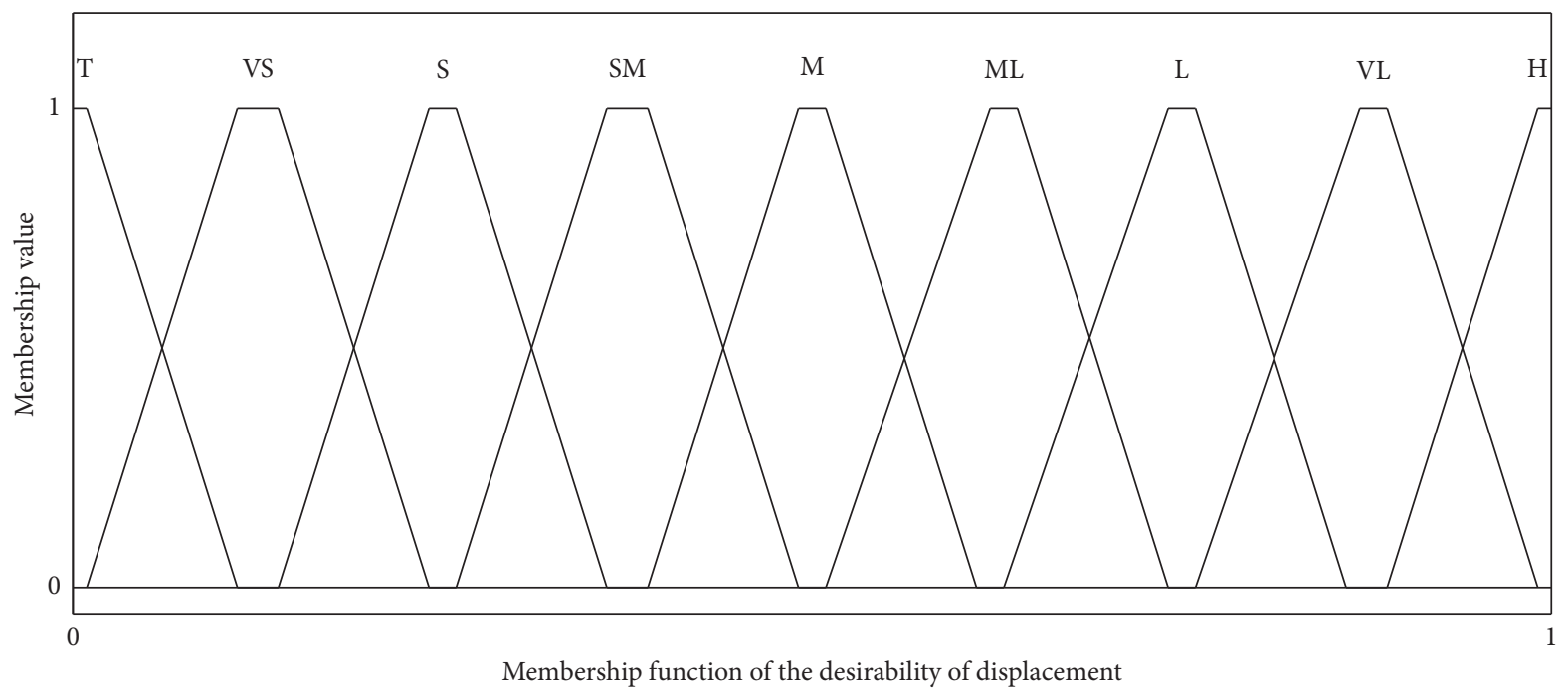

(b)

FIgURE 10: Membership functions plot: (a) frequency; (b) displacement.

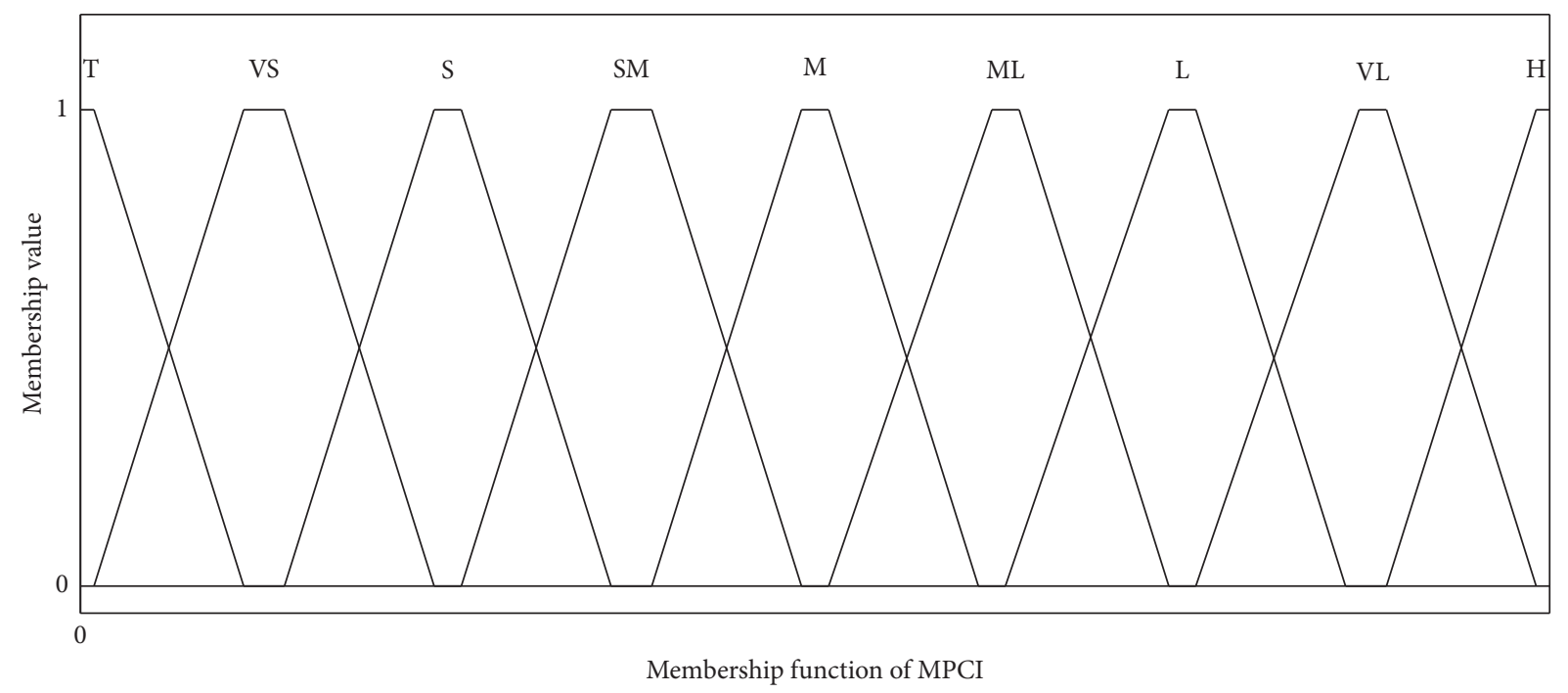

FIGURE 11: Membership functions plot for the MPCI.

4.2.4. Case Study 3. Based on the results of sensitivity analysis in Table 6 and Figure 9, the space of design variables is relatively shortened. Case study 3 also simultaneously maximizes $F_{1}(\mathbf{X})$ and maximizes $F_{2}(\mathbf{X})$. The computational principle is similar to previous cases. The statement of optimization is stated as follows. 
Table 8: Desirability results of the case study 1 .

\begin{tabular}{|c|c|c|c|c|c|c|c|c|}
\hline \multirow{2}{*}{ No. } & \multicolumn{3}{|c|}{ Design variables (unit: mm) } & \multirow{2}{*}{$\begin{array}{l}\text { Frequency } \\
F_{1}(\mathrm{X})(\mathrm{Hz}) \\
\end{array}$} & \multirow{2}{*}{$\begin{array}{c}\text { Frequency } \\
F_{2}(\mathrm{X})(\mathrm{mm})\end{array}$} & \multirow{2}{*}{$\begin{array}{c}\text { Stress } \\
F_{3}(\mathrm{X})(\mathrm{MPa})\end{array}$} & \multirow{2}{*}{$\begin{array}{c}\text { Desirability of } F_{1}(\mathrm{X}) \\
D_{1}\end{array}$} & \multirow{2}{*}{$\begin{array}{c}\text { Desirability of } F_{2}(\mathrm{X}) \\
\mathrm{D}_{2}\end{array}$} \\
\hline & $D$ & $L_{3}$ & $L_{4}$ & & & & & \\
\hline 1 & 2.875 & 10.1625 & 16.35 & 145.7347 & 0.010851 & 18.4667631 & 0.167540611 & 0.032475676 \\
\hline 2 & 2.25 & 10.1625 & 16.35 & 27.81286 & 0.079585 & 147.3155439 & 0.004206109 & 0.51031939 \\
\hline 3 & 3.5 & 10.1625 & 16.35 & 684.6259 & $1.93 E-05$ & 2.059713964 & 0.91132379 & 0 \\
\hline 4 & 2.875 & 8.5 & 16.35 & 152.266 & 0.010928 & 17.72299244 & 0.186110214 & 0.065979996 \\
\hline 5 & 2.875 & 11.825 & 16.35 & 139.8676 & 0.010781 & 18.28006101 & 0.149565911 & 0.067869119 \\
\hline 6 & 2.875 & 10.1625 & 14 & 156.5233 & 0.007468 & 16.80767677 & 0.190016733 & 0 \\
\hline 7 & 2.875 & 10.1625 & 18.7 & 136.4378 & 0.01453 & 23.57711698 & 0.146800947 & 0.230293298 \\
\hline 8 & 2.25 & 8.5 & 14 & 32.2812 & 0.036407 & 85.94278072 & 0.008724268 & 0.218602991 \\
\hline 9 & 3.5 & 8.5 & 14 & 749.2335 & $1.84 E-05$ & 2.584933531 & 0.993446922 & 0.051737375 \\
\hline 10 & 2.25 & 11.825 & 14 & 29.85823 & 0.036103 & 84.18491871 & 0.006099755 & 0.219639916 \\
\hline 11 & 3.5 & 11.825 & 14 & 685.0373 & $2.24 E-05$ & 2.116902014 & 0.91388315 & 0.047684449 \\
\hline 12 & 2.25 & 8.5 & 18.7 & 26.21778 & 0.178381 & 262.0338394 & $9.3986 E-05$ & 0.93699663 \\
\hline 13 & 3.5 & 8.5 & 18.7 & 680.4317 & $1.69 E-05$ & 2.38866496 & 0.906545952 & 0 \\
\hline 14 & 2.25 & 11.825 & 18.7 & 24.3866 & 0.18053 & 265.9814502 & 0.006569152 & 0.9448278 \\
\hline 15 & 3.5 & 11.825 & 18.7 & 628.8354 & $2.03 E-05$ & 2.115335728 & 0.836081859 & 0 \\
\hline
\end{tabular}

TABle 9: Fuzzy rules matrix for case 1.

\begin{tabular}{|c|c|c|c|}
\hline No. & Desirability for $F_{1}(\mathrm{X})$ & Desirability for $F_{2}(\mathrm{X})$ & MPCI \\
\hline 1 & $\mathrm{~S}$ & $\mathrm{~T}$ & $\mathrm{~T}$ \\
\hline 2 & M & $\mathrm{T}$ & VS \\
\hline 3 & $\mathrm{~L}$ & $\mathrm{~T}$ & S \\
\hline 4 & $\mathrm{~S}$ & VS & VS \\
\hline 5 & M & VS & S \\
\hline 6 & $\mathrm{~L}$ & VS & SM \\
\hline 7 & $\mathrm{~S}$ & S & S \\
\hline 8 & M & S & SM \\
\hline 9 & $\mathrm{~L}$ & $\mathrm{~S}$ & ML \\
\hline 10 & $\mathrm{~S}$ & SM & S \\
\hline 11 & M & SM & SM \\
\hline 12 & $\mathrm{~L}$ & SM & M \\
\hline 13 & $\mathrm{~S}$ & $\mathrm{M}$ & SM \\
\hline 14 & M & M & M \\
\hline 15 & $\mathrm{~L}$ & $\mathrm{M}$ & ML \\
\hline 16 & S & ML & SM \\
\hline 17 & M & ML & $\mathrm{M}$ \\
\hline 18 & $\mathrm{~L}$ & ML & ML \\
\hline 19 & $\mathrm{~S}$ & $\mathrm{~L}$ & ML \\
\hline 20 & $\mathrm{M}$ & $\mathrm{L}$ & $\mathrm{ML}$ \\
\hline 21 & $\mathrm{~L}$ & $\mathrm{~L}$ & $\mathrm{~L}$ \\
\hline 22 & $S$ & VL & $\mathrm{ML}$ \\
\hline 23 & $\mathrm{M}$ & VL & $\mathrm{L}$ \\
\hline 24 & $\mathrm{~L}$ & VL & VL \\
\hline 25 & $\mathrm{~S}$ & $\mathrm{H}$ & $\mathrm{ML}$ \\
\hline 26 & M & $\mathrm{H}$ & L \\
\hline 27 & $\mathrm{~L}$ & $\mathrm{H}$ & $\mathrm{H}$ \\
\hline
\end{tabular}




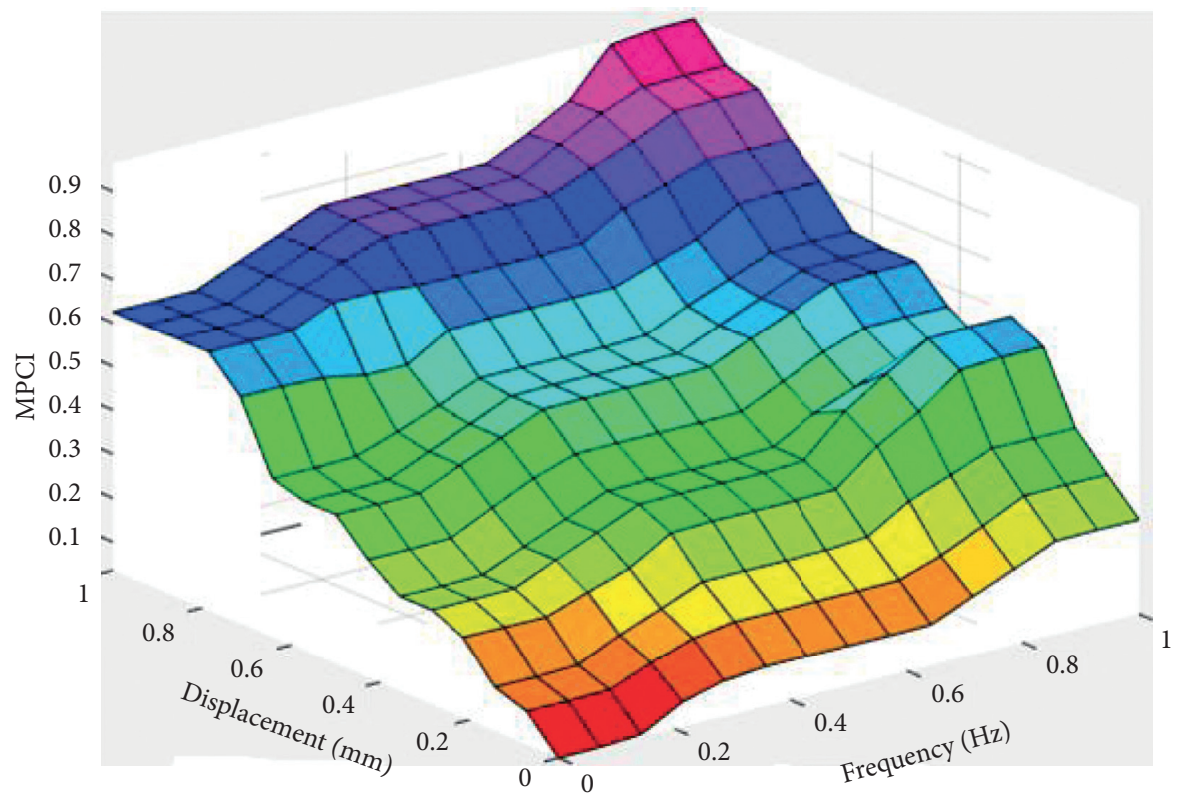

FIgURE 12: Plot of input vs. output in the FIS system.

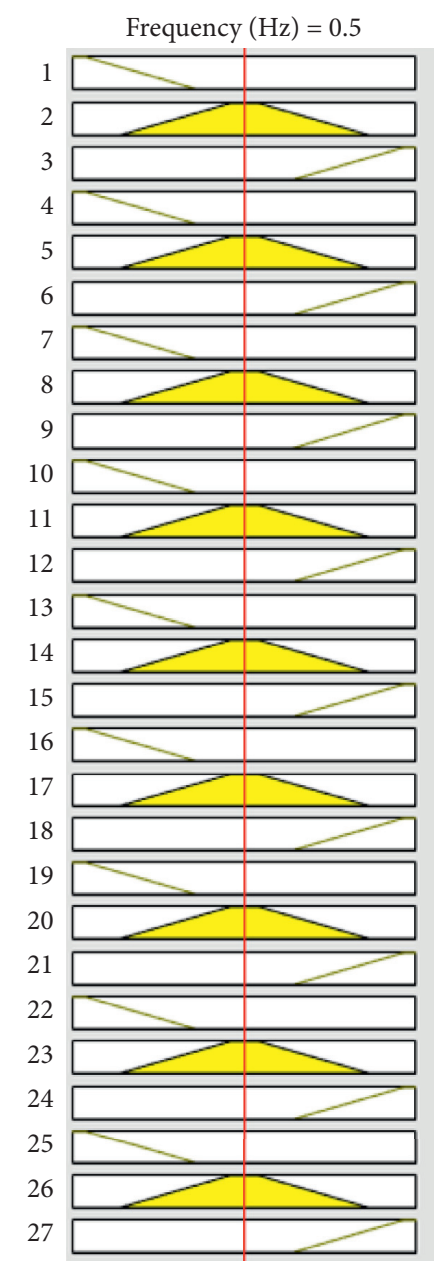

Displacement $(\mathrm{mm})=0.5$

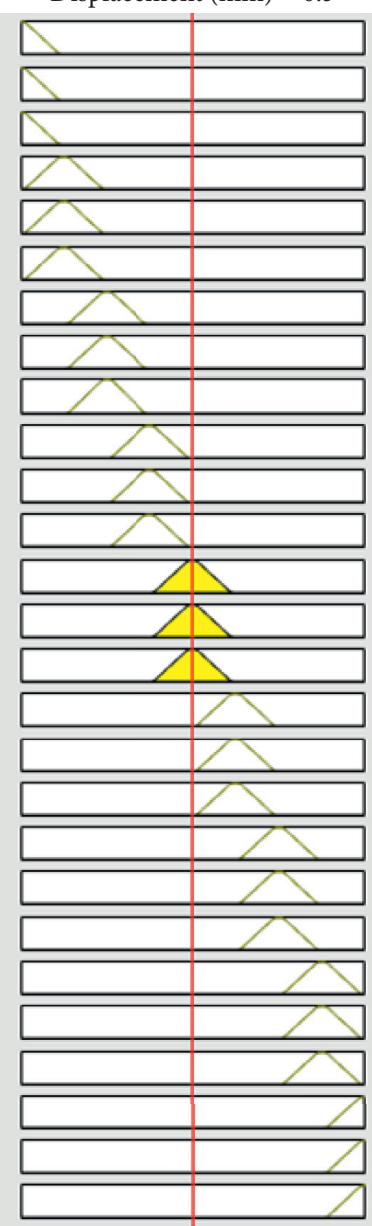

Figure 13: Twenty-seven fuzzy rules.

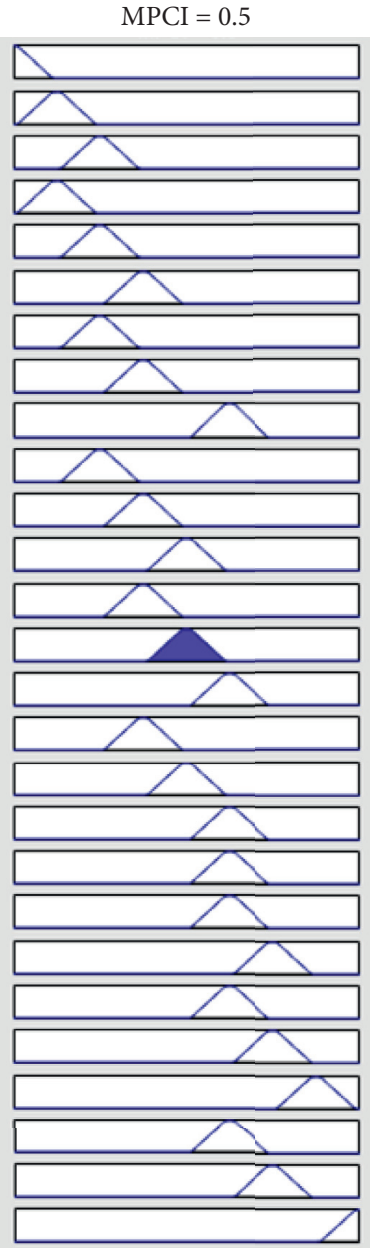

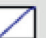


TABle 10: Results of fuzzy MPCI for case 1.

\begin{tabular}{lccc}
\hline No. & Desirability of $F_{1}(\mathrm{X})$ & Desirability of $F_{2}(\mathrm{X})$ & MPCI \\
\hline 1 & 0.167540611 & 0.032475676 & 0.107 \\
2 & 0.004206109 & 0.51031939 & 0.375 \\
3 & 0.91132379 & 0 & 0.25 \\
4 & 0.186110214 & 0.065979996 & 0.133 \\
5 & 0.149565911 & 0.067869119 & 0.114 \\
6 & 0.190016733 & 0 & 0.0779 \\
7 & 0.146800947 & 0.230293298 & 0.24 \\
8 & 0.008724268 & 0.218602991 & 0.222 \\
9 & 0.993446922 & 0.051737375 & 0.301 \\
10 & 0.006099755 & 0.219639916 & 0.223 \\
11 & 0.91388315 & 0.047684449 & 0.297 \\
12 & $9.3986 E-05$ & 0.93699663 & 0.625 \\
13 & 0.906545952 & 0 & 0.25 \\
14 & 0.006569152 & 0.9448278 & 0.625 \\
15 & 0.836081859 & 0 & 0.235 \\
\hline
\end{tabular}

TABLE 11: ANFIS parameters for case 1.

\section{Number of nodes}

Number of linear parameters

Number of nonlinear parameters

Total number of parameters

Number of training data pairs

Number of testing data pairs

Number of fuzzy rules

Find design variable $\mathbf{X}=\left[L_{1}, L_{3}, D\right]^{\mathrm{T}}$ :

$$
\text { Maximize } \operatorname{MPCI}(\mathbf{X})_{\text {case study } 3}
$$

s.t.

$$
\left\{\begin{array}{l}
F_{3}(\mathbf{X}) \leq \frac{\sigma_{a}}{\mathrm{SF}} \\
4.9 \mathrm{~mm} \leq L_{1} \leq 7.7 \mathrm{~mm}, \\
8.5 \mathrm{~mm} \leq L_{3} \leq 11.825 \mathrm{~mm}, \\
2.25 \mathrm{~mm} \leq D \leq 3.5 \mathrm{~mm} .
\end{array}\right.
$$

Case study 3 regards three design variables and two objective functions and one constraint. CCD is used to build 15 numerical experiments. The results of frequency, displacement, and equivalent stress are collected. And then, desirability of two responses is calculated, as given in $\mathrm{Ta}$ ble 18. The results found all stress values are smaller than the allowable stress of the proposed material.

The MFs for desirability of frequency include three levels, and the desirability of displacement is consisted of seven levels, while the MFs of fuzzy MPCI output are divided into seven levels. Subsequently, a matrix of fuzzy rules is built in Table 19. The value of MPCI is determined according to each value of desirability for objective functions, as given in Table 20.

Subsequently, using the values of design variables in Table 18 and the MPCI value of Table 20, the ANFIS model is formed for mapping the design variables and the MPCI. The ANFIS parameters for case study 2 are given in Table 21. The predicting accuracy of the ANFIS model is well confirmed through equations (29) and (31) prior to implement the MOO problem for the SRCM.

By using the TMFL, the optimal parameters are determined at $L_{1}=7.7 \mathrm{~mm}, L_{3}=10.1625 \mathrm{~mm}$, and $D=2.25 \mathrm{~mm}$, as shown in Table 22. Based on the TMFL, the optimal frequency and displacement are found at $158.970 \mathrm{~Hz}$ and $0.0957 \mathrm{~mm}$, respectively. Such optimal points are local optimum solutions. Subsequently, the results of proposed hybrid methodology found that the optimal design parameters are at $L_{1}=6.3793 \mathrm{~mm}, L_{3}=9.73 \mathrm{~mm}$, and $D=2.25 \mathrm{~mm}$. Using these, the proposed approach, the optimal frequency, and displacement are found at $27.006 \mathrm{~Hz}$ and $0.2203 \mathrm{~mm}$, respectively. At last, the predicted MPCI from the proposed methodology is effective and better than that from the TMFL. In addition, the equivalent stress is also lower than the allowable stress. The optimal results are satisfied with designer's requirements.

\section{Results and Discussion}

As discussed above, three cases studies are taken as numerical examples to describe application capacity and effectiveness of the proposed method. The performances of proposed methodology are compared with the TMFL. Table 23 summarizes all the optimal solutions for this comparison. In each case study, the optimal parameters are used to create a 3D model in SolidWorks 2018 software and then imported into ANSYS 2018 software to evaluate the robustness of the proposed hybrid approach by calculating the relative error. This error is calculated as follows:

$$
\varepsilon(\%)=\left(\frac{R_{p}-R_{a}}{R_{a}}-1\right) * 100,
$$

where $\varepsilon, R_{p}$, and $R_{a}$ represent the relative error, predicted result from proposed method, and actual result, respectively.

Case study 1: using the TMFL, the results found the optimal frequency and displacement are $24.4574 \mathrm{~Hz}$ and $0.1691 \mathrm{~mm}$, respectively. Meanwhile, the proposed hybrid approach predicts the frequency and displacement are about $26.592 \mathrm{~Hz}$ and $0.1679 \mathrm{~mm}$, respectively. By using the proposed method, the relative errors between predicted values and FEA values are very small (around 5\%), while the error value is around $7 \%$ via using TMFL. Both the proposed methods are reliable tools in this case. According to the Taguchi method, a larger-the-better value of MPCI is a desired value for the MOO problem. On the contrary, the proposed hybrid approach has a better performance than the TMFL because the MPCI from the proposed method is higher than that from the TMFL.

Case study 2: through the TMFL, the results found the optimal frequency and displacement are $28.9482 \mathrm{~Hz}$ and $0.1527 \mathrm{~mm}$, respectively. By using the proposed hybrid integration, the optimal frequency and displacement are found at $651.08 \mathrm{~Hz}$ and $0.1981 \mathrm{~mm}$, respectively. By using the proposed hybrid approach, the relative errors between 
TABLe 12: Comparison of different methods for case study 1.

\begin{tabular}{|c|c|c|c|c|c|c|}
\hline \multirow[b]{2}{*}{ Method } & \multirow[b]{2}{*}{$\begin{array}{c}\text { Optimal } \\
\text { parameters }\end{array}$} & \multicolumn{5}{|c|}{ Optimal results } \\
\hline & & $\begin{array}{l}\text { Frequency } \\
\quad(\mathrm{Hz})\end{array}$ & $\begin{array}{l}\text { Displacement } \\
(\mathrm{mm})\end{array}$ & $\begin{array}{l}\text { Stress } \\
(\mathrm{MPa})\end{array}$ & SF & MPCI \\
\hline Hybrid of Taguchi method and fuzzy logic & $\begin{array}{c}D=2.25 \mathrm{~mm} \\
L_{3}=8.5 \mathrm{~mm} \\
L_{4}=18.7 \mathrm{~mm}\end{array}$ & 24.4574 & 0.1691 & 251.463 & 2 & 0.510 \\
\hline $\begin{array}{l}\text { Proposed approach of desirability, fuzzy-ANFIS- } \\
\text { LAPO algorithm }\end{array}$ & $\begin{array}{c}D=2.30 \\
L_{3}=8.5 \mathrm{~mm} \\
L_{4}=18.7 \mathrm{~mm}\end{array}$ & 26.592 & 0.1539 & 253.847 & 1.98 & 0.570 \\
\hline
\end{tabular}

TABLE 13: Desirability results of the case study 2.

\begin{tabular}{|c|c|c|c|c|c|c|c|c|c|}
\hline \multirow{2}{*}{ No. } & \multicolumn{4}{|c|}{ Design variables (unit: mm) } & \multirow{2}{*}{$\begin{array}{l}\text { Frequency } \\
F_{1}(\mathrm{X}) \mathrm{mm}\end{array}$} & \multirow{2}{*}{$\begin{array}{c}\text { displacement } \\
F_{2}(\mathrm{X})(\mathrm{Hz})\end{array}$} & \multirow{2}{*}{$\begin{array}{c}\text { Stress } \\
F_{3}(\mathrm{X})(\mathrm{MPa})\end{array}$} & \multirow{2}{*}{$\begin{array}{c}\text { Desirability of } F_{1}(\mathrm{X}) \\
D_{1}\end{array}$} & \multirow{2}{*}{$\begin{array}{c}\text { Desirability of } F_{2}(\mathrm{X}) \\
\mathrm{D}_{2}\end{array}$} \\
\hline & $\theta$ & $L_{1}$ & $L_{2}$ & $D$ & & & & & \\
\hline 1 & 14.5 & 6.3 & 16.6 & 2.875 & 140.2838 & 0.013508 & 20.136932 & 0.126042291 & 0.102725633 \\
\hline 2 & 12.5 & 6.3 & 16.6 & 2.875 & 141.5087 & 0.010046 & 17.092119 & 0.089296146 & 0.049191484 \\
\hline 3 & 16.5 & 6.3 & 16.6 & 2.875 & 139.9513 & 0.013255 & 20.756254 & 0.264504072 & 0.098396331 \\
\hline 4 & 14.5 & 4.9 & 16.6 & 2.875 & 139.9384 & 0.010927 & 18.907122 & 0.016411556 & 0.055559464 \\
\hline 5 & 14.5 & 7.7 & 16.6 & 2.875 & 142.1834 & 0.010787 & 20.473748 & 0.338359234 & 0.081632844 \\
\hline 6 & 14.5 & 6.3 & 14.5 & 2.875 & 148.7576 & 0.008941 & 13.90206 & 0.105418876 & 0.070044602 \\
\hline 7 & 14.5 & 6.3 & 18.7 & 2.875 & 133.6071 & 0.011627 & 18.555608 & 0.249708039 & 0.059644029 \\
\hline 8 & 14.5 & 6.3 & 16.6 & 2.25 & 54.02425 & 0.091965 & 155.65601 & 0 & 0.520514669 \\
\hline 9 & 14.5 & 6.3 & 16.6 & 3.5 & 224.1544 & 0.004473 & 12.163485 & 0.375575312 & 0.106083045 \\
\hline 10 & 12.5 & 4.9 & 14.5 & 2.25 & 29.63534 & 0.010148 & 31.923139 & 0.036724691 & 0.150747816 \\
\hline 11 & 16.5 & 4.9 & 14.5 & 2.25 & 30.0422 & 0.040185 & 87.9122 & 0.013316419 & 0.413327968 \\
\hline 12 & 12.5 & 7.7 & 14.5 & 2.25 & 30.81703 & 0.055528 & 108.84574 & 0 & 0.456367237 \\
\hline 13 & 16.5 & 7.7 & 14.5 & 2.25 & 28.94823 & 0.152702 & 249.32714 & 0.214726673 & 0.70638882 \\
\hline 14 & 12.5 & 4.9 & 18.7 & 2.25 & 26.82343 & 0.086202 & 160.20452 & 0.022707379 & 0.504418284 \\
\hline 15 & 16.5 & 4.9 & 18.7 & 2.25 & 24.99238 & 0.0898 & 160.62031 & 0.05839604 & 0.461010103 \\
\hline 16 & 12.5 & 7.7 & 18.7 & 2.25 & 25.76424 & 0.065583 & 119.20462 & 0.19869231 & 0.36014185 \\
\hline 17 & 16.5 & 7.7 & 18.7 & 2.25 & 649.3008 & $1.78 E-05$ & 7.9628582 & 0.632518439 & 0.304175099 \\
\hline 18 & 12.5 & 4.9 & 14.5 & 3.5 & 238.0543 & 0.002067 & 7.4382126 & 0.393236144 & 0 \\
\hline 19 & 16.5 & 4.9 & 14.5 & 3.5 & 235.5158 & 0.003742 & 12.915726 & 0.309825869 & 0 \\
\hline 20 & 12.5 & 7.7 & 14.5 & 3.5 & 245.0752 & 0.003262 & 8.3554397 & 0.463009101 & 0.033847584 \\
\hline 21 & 16.5 & 7.7 & 14.5 & 3.5 & 706.8922 & $1.89 E-05$ & 2.0140876 & 0.777736293 & 0.175665459 \\
\hline 22 & 12.5 & 4.9 & 18.7 & 3.5 & 212.0324 & 0.004153 & 11.315538 & 0.264022704 & 0.206278396 \\
\hline 23 & 16.5 & 4.9 & 18.7 & 3.5 & 211.4283 & 0.004882 & 10.593629 & 0.239709361 & 0.054666508 \\
\hline 24 & 12.5 & 7.7 & 18.7 & 3.5 & 648.699 & $1.77 E-05$ & 2.1232273 & 0.706507805 & 0 \\
\hline 25 & 16.5 & 7.7 & 18.7 & 3.5 & 646.6069 & $1.97 E-05$ & 1.998213 & 1 & 0 \\
\hline
\end{tabular}

predicted values and simulated values are around $4.65 \%$, while the error between the predicted value by the TMFL and FEA value is around 9.5\%. In addition, the MPCI predicted by the proposed hybrid approach is greater than that from TMFL. In other words, the performance and prediction accuracy of proposed methodology outperforms the TMFL.

Case study 3: the results found the optimal frequency and displacement are $158.970 \mathrm{~Hz}$ and $0.0957 \mathrm{~mm}$, respectively, by using TMFL. Meanwhile, the proposed hybrid approach finds the optimal frequency and displacement approximately $651.08 \mathrm{~Hz}$ and $0.1981 \mathrm{~mm}$, respectively. The relative errors between predicted values and simulated values are around 6\%, while the error between the TMFL and FEA is about $484 \%$. Moreover, the MPCI predicted by the proposed hybrid approach is higher than that from TMFL. It can conclude that the performance and precision of the proposed approach outperforms the TMFL.
The results of three numerical examples show that the proposed optimization scheme is better than the traditional TMFL. Among three numerical examples, case study 3 may be chosen as an optimal solution for MOO design of the SRCM because the MPCI is the highest value. The optimal design variables are at $L_{1}=6.3793 \mathrm{~mm}, L_{3}=9.73 \mathrm{~mm}$, and $D=2.25 \mathrm{~mm}$. Other remain parameters are constant values. It concludes that the proposed hybrid approach is a robust optimization tool and effectiveness for solving the MOO design for the mechanism and related complex optimization fields.

\section{Comparison with Metaheuristic Optimization Algorithms}

As discussed above, the proposed method outperformed the traditional TMFL to solve MOO design for the mechanism. Continuously, the proposed algorithm is compared with 
Table 14: Fuzzy rules matrix for case 2.

\begin{tabular}{|c|c|c|c|}
\hline No. & Desirability for $F_{1}(\mathrm{X})$ & Desirability for $F_{2}(\mathrm{X})$ & MPCI \\
\hline 1 & $\mathrm{~S}$ & $\mathrm{~T}$ & $\mathrm{~T}$ \\
\hline 2 & M & $\mathrm{T}$ & VS \\
\hline 3 & $\mathrm{~L}$ & $\mathrm{~T}$ & S \\
\hline 4 & $\mathrm{~S}$ & VS & VS \\
\hline 5 & M & VS & S \\
\hline 6 & $\mathrm{~L}$ & VS & $\mathrm{SM}$ \\
\hline 7 & $S$ & S & S \\
\hline 8 & M & S & SM \\
\hline 9 & $\mathrm{~L}$ & S & ML \\
\hline 10 & $\mathrm{~S}$ & SM & $\mathrm{S}$ \\
\hline 11 & M & SM & $\mathrm{SM}$ \\
\hline 12 & $\mathrm{~L}$ & SM & M \\
\hline 13 & $S$ & M & SM \\
\hline 14 & M & M & $\mathrm{M}$ \\
\hline 15 & $\mathrm{~L}$ & M & ML \\
\hline 16 & $S$ & ML & SM \\
\hline 17 & M & ML & $\mathrm{M}$ \\
\hline 18 & $\mathrm{~L}$ & ML & ML \\
\hline 19 & $\mathrm{~S}$ & $\mathrm{~L}$ & ML \\
\hline 20 & M & $\mathrm{L}$ & $\mathrm{ML}$ \\
\hline 21 & $\mathrm{~L}$ & $\mathrm{~L}$ & $\mathrm{~L}$ \\
\hline 22 & $S$ & VL & $\mathrm{ML}$ \\
\hline 23 & $\mathrm{M}$ & VL & $\mathrm{L}$ \\
\hline 24 & $\mathrm{~L}$ & VL & VL \\
\hline 25 & $S$ & $\mathrm{H}$ & $\mathrm{ML}$ \\
\hline 26 & $\mathrm{M}$ & $\mathrm{H}$ & $\mathrm{L}$ \\
\hline 27 & $\mathrm{~L}$ & $\mathrm{H}$ & $\mathrm{H}$ \\
\hline
\end{tabular}

TABLE 15: Results of fuzzy MPCI for case 2.

\begin{tabular}{|c|c|c|c|}
\hline No. & Desirability for $F_{1}(\mathrm{X})$ & Desirability for $F_{2}(\mathrm{X})$ & MPCI \\
\hline 1 & 0.126042291 & 0.102725633 & 0.123 \\
\hline 2 & 0.089296146 & 0.049191484 & 0.0934 \\
\hline 3 & 0.264504072 & 0.098396331 & 0.19 \\
\hline 4 & 0.016411556 & 0.055559464 & 0.099 \\
\hline 5 & 0.338359234 & 0.081632844 & 0.204 \\
\hline 6 & 0.105418876 & 0.070044602 & 0.109 \\
\hline 7 & 0.249708039 & 0.059644029 & 0.17 \\
\hline 8 & 0 & 0.520514669 & 0.375 \\
\hline 9 & 0.375575312 & 0.106083045 & 0.238 \\
\hline 10 & 0.036724691 & 0.150747816 & 0.146 \\
\hline 11 & 0.013316419 & 0.413327968 & 0.286 \\
\hline 12 & 0 & 0.456367237 & 0.333 \\
\hline 13 & 0.214726673 & 0.70638882 & 0.517 \\
\hline 14 & 0.022707379 & 0.504418284 & 0.375 \\
\hline 15 & 0.05839604 & 0.461010103 & 0.338 \\
\hline 16 & 0.19869231 & 0.36014185 & 0.284 \\
\hline 17 & 0.632518439 & 0.304175099 & 0.375 \\
\hline 18 & 0.393236144 & 0 & 0.125 \\
\hline 19 & 0.309825869 & 0 & 0.12 \\
\hline 20 & 0.463009101 & 0.033847584 & 0.156 \\
\hline 21 & 0.777736293 & 0.175665459 & 0.445 \\
\hline 22 & 0.206278396 & 0.264022704 & 0.261 \\
\hline 23 & 0.054666508 & 0.239709361 & 0.163 \\
\hline 24 & 0 & 0.706507805 & 0.164 \\
\hline 25 & 0 & 1 & 0.25 \\
\hline
\end{tabular}

recent less-parameter optimization algorithms such as Jaya algorithm and TLBO algorithm. Case 3 is chosen as the final optimal candidate for the proposed mechanism. Therefore, the ANFIS structure of case 3 is then coupled with Jaya and TLBO algorithms for this comparison. The results indicated that the optimal frequency and displacement predicted by 
TABle 16: ANFIS parameters for case 2.

Number of nodes

Number of linear parameters

Number of nonlinear parameters

Total number of parameters

Number of training data pairs

Number of testing data pairs

TABle 17: Comparison of differential methods for case study 2.

\begin{tabular}{|c|c|c|c|c|c|c|}
\hline \multirow[b]{2}{*}{ Method } & \multirow[b]{2}{*}{$\begin{array}{c}\text { Optimal } \\
\text { parameters }\end{array}$} & \multicolumn{5}{|c|}{ Optimal results } \\
\hline & & $\begin{array}{l}\text { Frequency } \\
\qquad(\mathrm{Hz})\end{array}$ & $\begin{array}{l}\text { Displacement } \\
(\mathrm{mm})\end{array}$ & $\begin{array}{l}\text { Stress } \\
(\mathrm{MPa})\end{array}$ & SF & MPCI \\
\hline Hybrid of Taguchi method and fuzzy logic & $\begin{array}{c}\theta=16.5^{\circ} \\
L_{1}=7.7 \mathrm{~mm} \\
L_{2}=18.7 \mathrm{~mm} \\
D=2.25 \mathrm{~mm} \\
\theta=16.5^{\circ}\end{array}$ & 28.94823 & 0.1527 & 7.9628 & 63.16 & 0.375 \\
\hline $\begin{array}{l}\text { Proposed approach of desirability, fuzzy-ANFIS- } \\
\text { LAPO algorithm }\end{array}$ & $\begin{array}{c}L_{1}=8.0 \mathrm{~mm} \\
L_{2}=14.5 \mathrm{~mm} \\
D=2.5 \mathrm{~mm}\end{array}$ & 651.08 & 0.1981 & 4.4641 & 112.67 & 0.517 \\
\hline
\end{tabular}

TABle 18: Desirability results of the case study 3.

\begin{tabular}{|c|c|c|c|c|c|c|c|c|}
\hline \multirow[t]{2}{*}{ No. } & \multicolumn{3}{|c|}{$\begin{array}{l}\text { Design variables (unit: } \\
\text { mm) }\end{array}$} & \multirow{2}{*}{$\begin{array}{l}\text { Frequency } \\
F_{1}(\mathrm{X})(\mathrm{Hz})\end{array}$} & \multirow{2}{*}{$\begin{array}{l}\text { Displacement } \\
F_{2}(\mathrm{X})(\mathrm{mm})\end{array}$} & \multirow{2}{*}{$\begin{array}{c}\text { Stress } \\
F_{3}(\mathrm{X})(\mathrm{MPa})\end{array}$} & \multirow{2}{*}{$\begin{array}{c}\text { Desirability of } F_{1}(\mathrm{X}) \\
\qquad D_{1}\end{array}$} & \multirow{2}{*}{$\begin{array}{c}\text { Desirability of } F_{2}(\mathrm{X}) \\
\qquad D_{2}\end{array}$} \\
\hline & $L_{1}$ & $L_{3}$ & $D$ & & & & & \\
\hline 1 & 6.3 & 10.1625 & 2.875 & 142.1428 & 0.013839 & 20.34068 & 0.257697 & 0.159738122 \\
\hline 2 & 4.9 & 10.1625 & 2.875 & 135.4637 & 0.01317 & 21.402 & 0.327272 & 0.085867476 \\
\hline 3 & 7.7 & 10.1625 & 2.875 & 684.347 & $1.76 E-05$ & 2.829244 & 0.752914 & 0 \\
\hline 4 & 6.3 & 10.1625 & 2.25 & 27.02455 & 0.242625 & 365.8681 & 0 & 0.726699252 \\
\hline 5 & 6.3 & 10.1625 & 3.5 & 260.1458 & 0.004596 & 10.77186 & 0.434028 & 0.240793486 \\
\hline 6 & 6.3 & 8.5 & 2.875 & 147.0101 & 0.013744 & 20.2492 & 0.158614 & 0.030275021 \\
\hline 7 & 6.3 & 11.825 & 2.875 & 135.084 & 0.013954 & 20.45499 & 0.133502 & 0.032371983 \\
\hline 8 & 4.9 & 8.5 & 2.25 & 29.8364 & 0.134483 & 238.4694 & 0 & 0.609908353 \\
\hline 9 & 7.7 & 8.5 & 2.25 & 28.4018 & 0.044736 & 83.66811 & 0.090806 & 0.265631968 \\
\hline 10 & 4.9 & 8.5 & 3.5 & 235.2483 & 0.00462 & 12.88278 & 0.242549 & 0 \\
\hline 11 & 7.7 & 8.5 & 3.5 & 708.6937 & $1.64 E-05$ & 2.275569 & 1 & 0 \\
\hline 12 & 4.9 & 11.825 & 2.25 & 27.5078 & 0.137112 & 235.3041 & 0 & 0.617415632 \\
\hline 13 & 7.7 & 11.825 & 2.25 & 26.37316 & 0.044389 & 85.38369 & 0.074579 & 0.266912238 \\
\hline 14 & 4.9 & 11.825 & 3.5 & 221.0946 & 0.004669 & 12.09392 & 0.208551 & 0 \\
\hline 15 & 7.7 & 11.825 & 3.5 & 653.4564 & $1.98 E-05$ & 2.137794 & 0.952076 & 0 \\
\hline
\end{tabular}

the proposed algorithm are better than those estimated by the Jaya and TLBO algorithms, as given in Table 24. On the contrary, the proposed methodology has a prediction accuracy better than other metaheuristic optimization algorithms.

In order to evaluate and validate the effectiveness of three abovementioned algorithms, the nonparametric tests are used for comparing the performances of the proposed hybrid approach with other algorithms [66, 67]. The Wilcoxon's rank signed test and Friedman test, two performance metrics, are utilized as the nonparametric tests. Both these statistical techniques consider that both different algorithms behave unsimilarly. Recently, the nonparametric tests have been widely applied in comparing the performances between algorithms, e.g., $[68,69]$. The comparing results are almost based on the $p$ value. In the present article, the computational simulations are conducted with 60 runs for each algorithm. The Wilcoxon's rank signed test is performed for frequency and displacement at 5\% significant level and 95\% confidence intervals. The statistical analysis is implemented in Minitab 18 software. The results in Tables 25 and 26 show that the $p$ value is less than 0.05 (5\% significance level). According to nonparametric tests $[66,67]$, it reveals that there is a statistical difference between the proposed approach and other algorithms. Besides, the results confirm that the proposed hybrid algorithm has a performance effectiveness greater than ANFIS-based Jaya and ANFIS-based TLBO algorithms. 
Table 19: Fuzzy rules matrix for case 3.

\begin{tabular}{|c|c|c|c|}
\hline No. & Desirability for $F_{1}(\mathrm{X})$ & Desirability for $F_{2}(\mathrm{X})$ & MPCI \\
\hline 1 & $\mathrm{~S}$ & $\mathrm{~T}$ & $\mathrm{~T}$ \\
\hline 2 & M & $\mathrm{T}$ & VS \\
\hline 3 & $\mathrm{~L}$ & $\mathrm{~T}$ & S \\
\hline 4 & S & VS & VS \\
\hline 5 & M & VS & S \\
\hline 6 & $\mathrm{~L}$ & VS & SM \\
\hline 7 & $\mathrm{~S}$ & S & S \\
\hline 8 & M & S & SM \\
\hline 9 & $\mathrm{~L}$ & S & ML \\
\hline 10 & $S$ & SM & S \\
\hline 11 & M & SM & SM \\
\hline 12 & $\mathrm{~L}$ & SM & $\mathrm{M}$ \\
\hline 13 & S & $\mathrm{M}$ & SM \\
\hline 14 & M & M & $\mathrm{M}$ \\
\hline 15 & $\mathrm{~L}$ & $\mathrm{M}$ & ML \\
\hline 16 & $S$ & ML & SM \\
\hline 17 & M & ML & $\mathrm{M}$ \\
\hline 18 & $\mathrm{~L}$ & ML & ML \\
\hline 19 & $\mathrm{~S}$ & $\mathrm{~L}$ & ML \\
\hline 20 & $\mathrm{M}$ & $\mathrm{L}$ & ML \\
\hline 21 & $\mathrm{~L}$ & $\mathrm{~L}$ & $\mathrm{~L}$ \\
\hline 22 & $S$ & $\mathrm{VL}$ & $\mathrm{ML}$ \\
\hline 23 & $\mathrm{M}$ & VL & $\mathrm{L}$ \\
\hline 24 & $\mathrm{~L}$ & VL & $\mathrm{VL}$ \\
\hline 25 & $S$ & $\mathrm{H}$ & ML \\
\hline 26 & $\mathrm{M}$ & $\mathrm{H}$ & $\mathrm{L}$ \\
\hline 27 & $\mathrm{~L}$ & $\mathrm{H}$ & $\mathrm{H}$ \\
\hline
\end{tabular}

TABLE 20: Results of fuzzy output for case 3.

\begin{tabular}{lccc}
\hline No. & Desirability for $F_{1}(\mathrm{X})$ & Desirability for $F_{2}(\mathrm{X})$ & MPCI \\
\hline 1 & 0.257697 & 0.159738122 & 0.237 \\
2 & 0.327272 & 0.085867476 & 0.205 \\
3 & 0.752914 & 0 & 0.189 \\
4 & 0 & 0.726699252 & 0.585 \\
5 & 0.434028 & 0.240793486 & 0.375 \\
6 & 0.158614 & 0.030275021 & 0.0958 \\
7 & 0.133502 & 0.032371983 & 0.0741 \\
8 & 0 & 0.609908353 & 0.375 \\
9 & 0.090806 & 0.265631968 & 0.25 \\
10 & 0.242549 & 0 & 0.105 \\
11 & 1 & 0 & 0.25 \\
12 & 0 & 0.617415632 & 0.375 \\
13 & 0.074579 & 0.266912238 & 0.25 \\
14 & 0.208551 & 0 & 0.0886 \\
15 & 0.952076 & 0 & 0.25 \\
\hline
\end{tabular}

TABLE 21: ANFIS parameters for case 3.

\begin{tabular}{lc}
\hline Number of nodes & 34 \\
Number of linear parameters & 32 \\
Number of nonlinear parameters & 18 \\
Total number of parameters & 50 \\
Number of training data pairs & 15 \\
Number of testing data pairs & 0 \\
Number of fuzzy rules & 8 \\
\hline
\end{tabular}

Another way, the Friedman test, is used for the behavior comparison of the abovementioned algorithms. The results find that the $p$ value is less than 0.05 . Therefore, it confirms that there the proposed hybrid approach differs from two other algorithms, as given in Tables 27 and 28. Moreover, the effectiveness of the proposed hybrid algorithm is better than ANFIS-based Jaya algorithm and ANFIS-based TLBO algorithm. Besides, the median responses for the proposed algorithm are greater than those of two other algorithms. So, 
TABLE 22: Comparison of differential methods for case study 3.

\begin{tabular}{|c|c|c|c|c|c|c|}
\hline \multirow[b]{2}{*}{ Method } & \multirow{2}{*}{$\begin{array}{l}\text { Optimal } \\
\text { parameters }\end{array}$} & \multicolumn{5}{|c|}{ Optimal results } \\
\hline & & $\begin{array}{l}\text { Frequency } \\
(\mathrm{Hz})\end{array}$ & $\begin{array}{l}\text { Displacement } \\
(\mathrm{mm})\end{array}$ & $\begin{array}{l}\text { Stress } \\
(\mathrm{MPa})\end{array}$ & SF & MPCI \\
\hline Hybrid of Taguchi method and fuzzy logic & $\begin{array}{c}L_{1}=7.7 \mathrm{~mm} \\
L_{3}=10.1625 \mathrm{~mm} \\
D=2.25 \mathrm{~mm}\end{array}$ & 158.970 & 0.0957 & 155.800 & 3.22 & 0.496 \\
\hline $\begin{array}{l}\text { Proposed approach of desirability, fuzzy-ANFIS- } \\
\text { LAPO algorithm }\end{array}$ & $\begin{array}{c}L_{1}=6.3793 \mathrm{~mm} \\
L_{3}=9.73 \mathrm{~mm} \\
D=2.25 \mathrm{~mm}\end{array}$ & 27.006 & 0.2203 & 332.8096 & 1.511 & 0.611 \\
\hline
\end{tabular}

TABLE 23: Comparison of the optimal results for three cases.

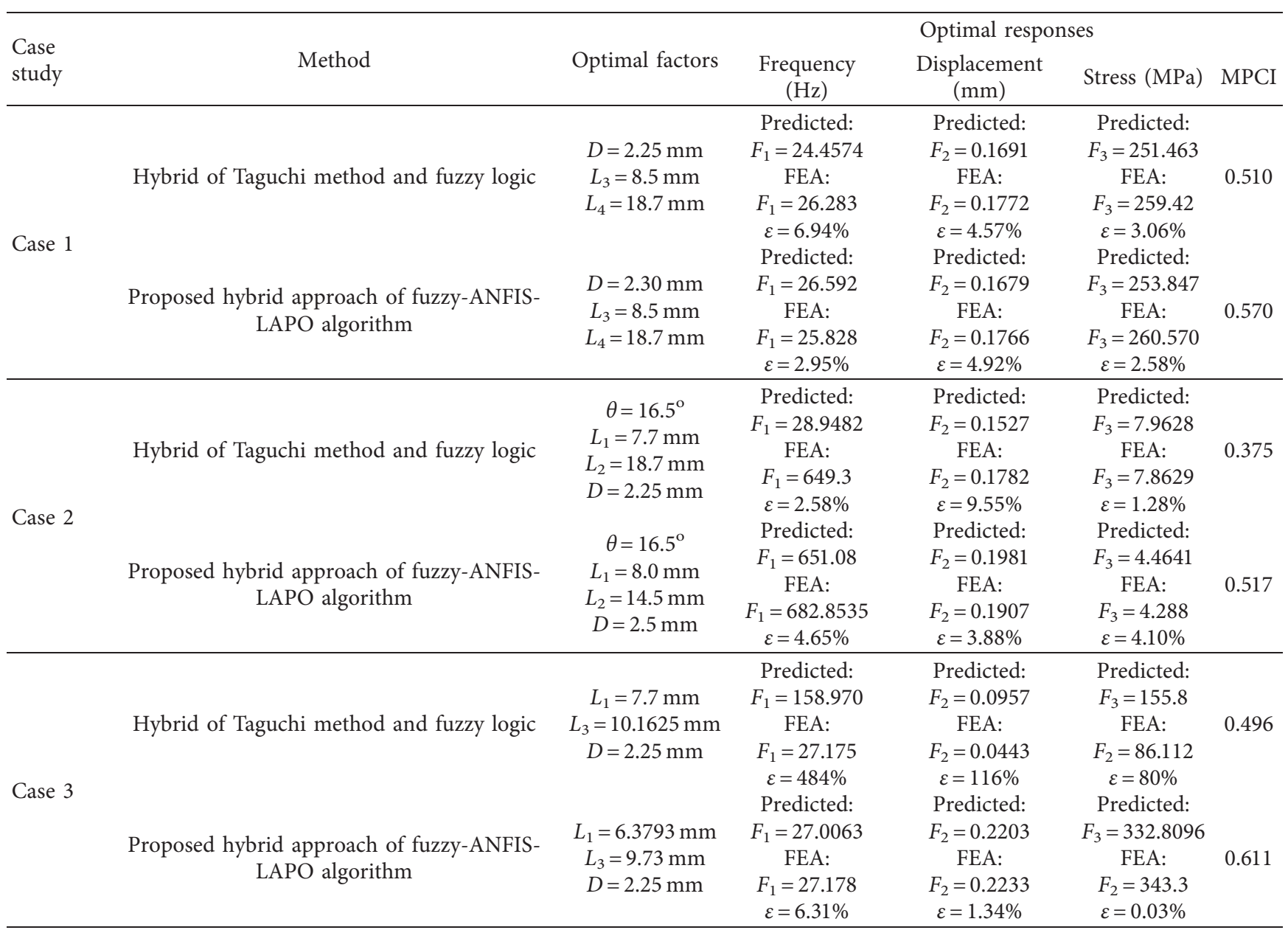

TABLE 24: Comparison between other algorithms with the proposed approach.

\begin{tabular}{lcc}
\hline Approaches & Frequency $(\mathrm{Hz})$ & Displacement $(\mathrm{mm})$ \\
\hline ANFIS-Jaya $\left(L_{1}=6.3790, L_{3}=9.7305 \mathrm{~mm}\right.$, and $\left.D=2.25 \mathrm{~mm}\right)$ & 26.6803 & 0.2199 \\
ANFIS-TLBO $\left(L_{1}=6.6134, L_{3}=10.8097 \mathrm{~mm}\right.$, and $\left.D=2.25 \mathrm{~mm}\right)$ & 26.0994 & 0.1959 \\
Proposed algorithm $\left(L_{1}=6.3793, L_{3}=9.7300 \mathrm{~mm}\right.$, and $\left.D=2.25 \mathrm{~mm}\right)$ & 27.0063 & 0.2203 \\
\hline
\end{tabular}

the proposed approach is a more effective tool than the other algorithms.

Although the proposed hybrid computational method has specific advantages in terms of solving MOO design of the SRCM, it has still some drawbacks: the running time is also long because the datasets are transferred into different stages. This may take a long time and high computational cost for more complex structures. It is known that the time 
TABLE 25: Wilcoxon signed rank test for displacement.

\begin{tabular}{lccc}
\hline Number of tests & & Proposed algorithm versus ANFIS-Jaya \\
60 & Wilcoxon statistic & $p$ value & Estimated median difference \\
\hline \multirow{2}{*}{ Number of tests } & 0.0 & 0.000 & -0.004 \\
60 & & Proposed algorithm versus ANFIS-TLBO & Estimated median difference \\
\hline
\end{tabular}

TABLE 26: Wilcoxon signed rank test for frequency.

\begin{tabular}{lccc}
\hline Number of tests & & Proposed algorithm versus ANFIS-Jaya \\
60 & Wilcoxon statistic & $p$ value & Estimated median difference \\
\hline Number of tests & 0.0 & 0.000 & -0.326 \\
60 & & Proposed algorithm versus ANFIS-TLBO & Estimated median difference \\
\hline
\end{tabular}

TABle 27: Friedman test for displacement.

\begin{tabular}{lccc}
\hline Algorithm & Number of tests & Median & Sum of ranks \\
\hline ANFIS-Jaya & 60 & 0.219900 & 120 \\
ANFIS-TLBO & 60 & 0.195900 & 0.220300 \\
Proposed algorithm & 60 & 0.212033 \\
Overall & 180 & $p$ value \\
DF & Chi-square & 0.000 \\
2 & 120 & H0: all treatment effects are zero \\
Null hypothesis & & H1: not all treatment effects are zero \\
Alternative hypothesis & &
\end{tabular}

TABLE 28: Friedman test for frequency.

\begin{tabular}{lccc}
\hline Algorithm & Number of tests & Median & Sum of ranks \\
\hline ANFIS-Jaya & 60 & 26.6803 & 120 \\
ANFIS-TLBO & 60 & 26.0994 \\
Proposed algorithm & 60 & 27.0063 \\
Overall & 180 & 26.5953 \\
DF & Chi-square & $p$ value \\
2 & 120 & 0.000 \\
Null hypothesis & & H0: all treatment effects are zero \\
Alternative hypothesis & & H1: not all treatment effects are zero \\
\hline
\end{tabular}

and space complexity of an algorithm is very important. For a more complicated problem with large datasets, it needs more better memory space of a computer. These disadvantages of the proposed method can be solved as follows: (i) FEM analysis is time consuming, but this problem can be solved by using parallelism computation by using multiple processors or a high-performance computer. (ii) Automatically adaptive combination of statistical method, FEM, and metaheuristic algorithms is a feasible approach to reduce the computational cost. In other words, the proposed optimization scheme should automatically update new data if there is an adjustment of space or range of design variables. The aim of the present work is to recommend a new hybrid computational approach in solving the MOO design for compliant mechanisms. In future work, the time, space, and algorithm complexity need to be investigated to improve the proposed approach.

\section{Conclusions}

A new hybrid computational method is developed to solve a MOO design for a Scott Russell compliant mechanism in this article. The methodology can be considered as a combination of statistical techniques, finite element method, and intelligent computation. It is an integration of the desirability function technique, fuzzy logic reasoning, ANFIS, and LAPO algorithm. A 3D FEM model is created, and CCD is used to build the experimental matrix. Next, numerical data are collected through FEM simulations. Based on the numerical results, a sensitivity investigation is analyzed by 
using ANOVA and Taguchi method. The refinement process for design variables is to determine really searching spaces of design parameters. As a result, three case studies are assigned as application example of the proposed approach. Next, the desirability of two responses is computed and transferred into the FIS system. ANFIS technique is then utilized to model the MPCI, which is considered as a combined objective function. LAPO algorithm is adopted for optimizing the MPCI. The results find that the predicting accuracy of proposed hybrid methodology is better than that of the traditional Taguchi-based fuzzy logic. Case study 3 is chosen to be optimal candidate. Finally, the Wilcoxon signed rank test and Friedman test are analyzed to compare the performances of the proposed approach with the ANFIS-based Jaya algorithm and ANFIS-based TLBO algorithm. The results found the performance efficiency of proposed approach is better than those of other approaches. The proposed methodology can be an efficient tool for more complex optimization problems, including multiple objective functions, design variables, and constraints.

The results of the present study will be extended to more complex compliant mechanisms. Future research will concentrate on fabricating physical prototypes, and then an extra number of testing experiments is performed to validate the theoretical models and simulations.

\section{Data Availability}

The data used to support the findings of this study are included within the article.

\section{Conflicts of Interest}

The authors declare that they have no conflicts of interest.

\section{Acknowledgments}

This research was funded by the Vietnam National Foundation for Science and Technology Development (NAFOSTED) under grant no. 107.01-2019.14.

\section{References}

[1] M. Ling, S. Chen, Q. Li, and G. Tian, "Dynamic stiffness matrix for free vibration analysis of flexure hinges based on non-uniform Timoshenko beam," Journal of Sound and Vibration, vol. 437, pp. 40-52, 2018.

[2] S.-C. Huang and T.-P. Dao, "Multi-objective optimal design of a 2-DOF flexure-based mechanism using hybrid approach of grey-Taguchi coupled response surface methodology and entropy measurement," Arabian Journal for Science and Engineering, vol. 41, 2016.

[3] M. Ling, J. Cao, Z. Jiang, and Q. Li, "Development of a multistage compliant mechanism with new boundary constraint," Review of Scientific Instruments, vol. 89, 2018.

[4] K.-B. Choi, J. J. Lee, G. H. Kim, H. J. Lim, and S. G. Kwon, "Amplification ratio analysis of a bridge-type mechanical amplification mechanism based on a fully compliant model," Mechanism and Machine Theory, vol. 121, pp. 355-372, 2018.

[5] S. Chen, M. Ling, and X. Zhang, "Design and experiment of a millimeter-range and high-frequency compliant mechanism with two output ports," Mechanism and Machine Theory, vol. 126, pp. 201-209, 2018.

[6] T. J. Teo, I.-M. Chen, G. Yang, and W. Lin, "A generic approximation model for analyzing large nonlinear deflection of beam-based flexure joints," Precision Engineering, vol. 34, no. 3, pp. 607-618, 2010.

[7] F. Parvari Rad, R. Vertechy, G. Berselli, and V. ParentiCastelli, "Analytical compliance analysis and finite element verification of spherical flexure hinges for spatial compliant mechanisms," Mechanism and Machine Theory, vol. 101, pp. 168-180, 2016.

[8] J. Wu, Y. Zhang, S. Cai, and J. Cui, "Modeling and analysis of conical-shaped notch flexure hinges based on NURBS," Mechanism and Machine Theory, vol. 128, 2018.

[9] A. Midha, L. L. Howell, and T. W. Norton, "Limit positions of compliant mechanisms using the pseudo-rigid-body model concept," Mechanism and Machine Theory, vol. 35, no. 1, pp. 99-115, 2000.

[10] N. Lobontiu, Compliant Mechanisms: Design of Flexure Hinges, CRC Press, Cleveland, OH, USA, 2002.

[11] Y. Koseki, T. Tanikawa, N. Koyachi, and T. Arai, "Kinematic analysis of a translational 3-d.o.f. micro-parallel mechanism using the matrix method," Advanced Robotics, vol. 16, no. 3, pp. 251-264, 2002.

[12] S. T. Smith, D. G. Chetwynd, and D. K. Bowen, "Design and assessment of monolithic high precision translation mechanisms," Journal of Physics E: Scientific Instruments, vol. 20, no. 8, pp. 977-983, 1987.

[13] S. Awtar and S. Sen, "A generalized constraint model for twodimensional beam flexures: nonlinear load-displacement formulation," Journal of Mechanical Design, vol. 132, no. 8, 2010.

[14] Q. Xu and Y. Li, "Analytical modeling, optimization and testing of a compound bridge-type compliant displacement amplifier," Mechanism and Machine Theory, vol. 46, no. 2, pp. 183-200, 2011.

[15] W.-L. Zhu, Z. Zhu, P. Guo, and B.-F. Ju, "A novel hybrid actuation mechanism based XY nanopositioning stage with totally decoupled kinematics," Mechanical Systems and Signal Processing, vol. 99, pp. 747-759, 2018.

[16] N. A. Menad, Z. Noureddine, A. Hemmati-Sarapardeh, and S. Shamshirband, "Modeling temperature-based oil-water relative permeability by integrating advanced intelligent models with grey wolf optimization: application to thermal enhanced oil recovery processes," Fuel, vol. 242, pp. 649-663, 2019.

[17] M. Dehghani, H. Riahi-Madvar, F. Hooshyaripor et al., "Prediction of hydropower generation using Grey wolf optimization adaptive neuro-fuzzy inference system," Energies, vol. 12, pp. 1-20, 2019.

[18] H. Riahi-Madvar, M. Dehghani, A. Seifi et al., "Comparative analysis of soft computing techniques RBF, MLP, and ANFIS with MLR and MNLR for predicting grade-control scour hole geometry," Engineering Applications of Computational Fluid Mechanics, vol. 13, no. 1, pp. 529-550, 2019.

[19] B. Zhu, X. Zhang, and N. Wang, “Topology optimization of hinge-free compliant mechanisms with multiple outputs using level set method," Structural and Multidisciplinary Optimization, vol. 47, no. 5, pp. 659-672, 2013.

[20] N. Wang, Z. Zhang, X. Zhang, and C. Cui, "Optimization of a 2-DOF micro-positioning stage using corrugated flexure units," Mechanism and Machine Theory, vol. 121, pp. 683-696, 2018.

[21] M. Liu, X. Zhang, and S. Fatikow, "Design and analysis of a high-accuracy flexure hinge," Review of Scientific Instruments, vol. 87, 2016. 
[22] T.-P. Dao and S.-C. Huang, "Design and multi-objective optimization for a broad self-amplified 2-DOF monolithic mechanism," Sādhanā, vol. 42, no. 9, pp. 1527-1542, 2017.

[23] K.-B. Choi and C. S. Han, "Optimal design of a compliant mechanism with circular notch flexure hinges," Proceedings of the Institution of Mechanical Engineers, Part C: Journal of Mechanical Engineering Science, vol. 221, no. 3, pp. 385-392, 2007.

[24] G. G. Fossati, L. F. F. Miguel, and W. J. P. Casas, "Multiobjective optimization of the suspension system parameters of a full vehicle model," Optimization and Engineering, vol. 20, no. 1, pp. 151-177, 2019.

[25] T.-P. Dao, N. L. Ho, T. T. Nguyen et al., "Analysis and optimization of a micro-displacement sensor for compliant microgripper," Microsystem Technologies, vol. 23, no. 12, pp. 5375-5395, 2017.

[26] M. Ling, J. Cao, Z. Jiang, and J. Lin, "A semi-analytical modeling method for the static and dynamic analysis of complex compliant mechanism," Precision Engineering, vol. 52, pp. 64-72, 2018.

[27] Y. Tian, B. Shirinzadeh, and D. Zhang, "Closed-form compliance equations of filleted V-shaped flexure hinges for compliant mechanism design," Precision Engineering, vol. 34, no. 3, pp. 408-418, 2010.

[28] N. R. Costa, J. Lourenço, and Z. L. Pereira, "Desirability function approach: a review and performance evaluation in adverse conditions," Chemometrics and Intelligent Laboratory Systems, vol. 107, no. 2, pp. 234-244, 2011.

[29] S.-C. Huang and T.-P. Dao, "Multi-objective optimal design of a 2-DOF flexure-based mechanism using hybrid approach of grey-Taguchi coupled response surface methodology and entropy measurement," Arabian Journal for Science and Engineering, vol. 41, no. 12, pp. 5215-5231, 2016.

[30] T.-P. Dao, "Multiresponse optimization of a compliant guiding mechanism using hybrid Taguchi-grey based fuzzy logic approach," Mathematical Problems in Engineering, vol. 2016, Article ID 5386893, 17 pages, 2016.

[31] M. V. Arasu, S. Arokiyaraj, P. Viayaraghavan et al., "One step green synthesis of larvicidal, and azo dye degrading antibacterial nanoparticles by response surface methodology," Journal of Photochemistry and Photobiology B: Biology, vol. 190, pp. 154-162, 2019.

[32] P. Jiang, C. Wang, Q. Zhou, X. Shao, L. Shu, and X. Li, "Optimization of laser welding process parameters of stainless steel 316L using FEM, Kriging and NSGA-II," Advances in Engineering Software, vol. 99, pp. 147-160, 2016.

[33] B. Wang, H. Moayedi, H. Nguyen, L. K. Foong, and A. S. A. Rashid, "Feasibility of a novel predictive technique based on artificial neural network optimized with particle swarm optimization estimating pullout bearing capacity of helical piles," Engineering with Computers, vol. 2019, pp. 1-10, 2019.

[34] M. Koopialipoor, A. Fahimifar, E. N. Ghaleini, M. Momenzadeh, and D. J. Armaghani, "Development of a new hybrid ANN for solving a geotechnical problem related to tunnel boring machine performance," Engineering with Computers, vol. 36, no. 1, pp. 345-357, 2019.

[35] L. Macura and M. Voznak, "Multi-criteria analysis and prediction of network incidents using monitoring system," Journal of Advanced Engineering and Computation, vol. 1, no. 1, p. 29, 2017.

[36] H. Moayedi, M. Raftari, A. Sharifi, W. A. W. Jusoh, and A. S. A. Rashid, "Optimization of ANFIS with GA and PSO estimating a ratio in driven piles," Engineering with Computers, vol. 36, no. 1, pp. 227-238, 2019.

[37] B. M. Sreedhara, M. Rao, and S. Mandal, "Application of an evolutionary technique (PSO-SVM) and ANFIS in clearwater scour depth prediction around bridge piers," Neural Computing and Applications, vol. 6, pp. 1-15, 2018.

[38] N. Le Chau, T. P. Dao, and V. A. Dang, "An efficient hybrid approach of improved adaptive neural fuzzy inference system and teaching learning-based optimization for design optimization of a jet pump-based thermoacoustic-Stirling heat engine," Neural Computing and Applications, vol. 2019, pp. 1-15, 2019.

[39] B. Najafi, S. F. Ardabili, A. Mosavi, S. Shamshirband, and T. Rabczuk, "An intelligent artificial neural network-response surface methodology method for accessing the optimum biodiesel and diesel fuel blending conditions in a diesel engine from the viewpoint of exergy and energy analysis," Energies, vol. 11, 2018.

[40] M. Ghalandari, A. Ziamolki, A. Mosavi, S. Shamshirband, K.-W. Chau, and S. Bornassi, "Aeromechanical optimization of first row compressor test stand blades using a hybrid machine learning model of genetic algorithm, artificial neural networks and design of experiments," Engineering Applications of Computational Fluid Mechanics, vol. 13, no. 1, pp. 892-904, 2019.

[41] A. Azareh, E. Rafiei Sardooi, B. Choubin et al., "Incorporating multi-criteria decision-making and fuzzy-value functions for flood susceptibility assessment," Geocarto International, vol. 2019, pp. 1-21, 2019.

[42] S. Shamshirband, M. Hadipoor, A. Baghban, A. Mosavi, J. Bukor, and A. R. Várkonyi-Kóczy, "Developing an ANFISPSO model to predict mercury emissions in combustion flue gases," Mathematics, vol. 7, pp. 1-16, 2019.

[43] M. Keshtiara, S. Golabi, and R. Tarkesh Esfahani, "Multiobjective optimization of stainless steel 304 tube laser forming process using GA," Engineering with Computers, vol. 2019, pp. 1-17, 2019.

[44] N. L. Chau, H. G. Le, T. Dao, M. P. Dang, and V. A. Dang, "Efficient hybrid method of FEA-based RSM and PSO algorithm for multi-objective optimization design for a compliant rotary joint for upper limb assistive device," Mathematical Problems in Engineering, vol. 2019, Article ID 2587373, 14 pages, 2019.

[45] T.-P. Dao, S.-C. Huang, and N. Le Chau, "Robust parameter design for a compliant microgripper based on hybrid Taguchidifferential evolution algorithm," Microsystem Technologies, vol. 24, no. 3, pp. 1461-1477, 2017.

[46] T.-P. Dao, S.-C. Huang, and P. T. Thang, "Hybrid Taguchicuckoo search algorithm for optimization of a compliant focus positioning platform," Appl. Soft Comput. J, vol. 57, 2017.

[47] R. Senkerik, I. Zelinka, and M. Pluhacek, "Chaos-based optimization - a review," Journal of Advanced Engineering and Computation, vol. 1, no. 1, p. 68, 2017.

[48] F. Zatloukal and J. Znoj, "Malware detection based on multiple PE headers identification and optimization for specific types of files," Journal of Advanced Engineering and Computation, vol. 1, no. 2, p. 153, 2017.

[49] I. Chernogorov, V. Polyakh, and O. Yarakhmedov, "Search optimization opportunities of modified self-organizing migrating algorithm in multi-extremal Tasks environment," Journal of Advanced Engineering and Computation, vol. 1, no. 2, p. 144, 2017. 
[50] D. Dinh-Cong, S. Pham-Duy, and T. Nguyen-Thoi, "Damage detection of $2 \mathrm{D}$ frame structures using incomplete measurements by optimization procedure and model reduction," Journal of Advanced Engineering and Computation, vol. 2, no. 3, p. 164, 2018.

[51] S. Shamshirband, A. Mosavi, and T. Rabczuk, "Particle swarm optimization model to predict scour depth around bridge pier," 2019, http://arxiv.org/abs/1906.08863v1.

[52] R. Venkata Rao, "Review of applications of tlbo algorithm and a tutorial for beginners to solve the unconstrained and constrained optimization problems," Decision Science Letters, vol. 5, pp. 1-30, 2016.

[53] H. Nenavath, D. R. Kumar Jatoth, and D. S. Das, “A synergy of the sine-cosine algorithm and particle swarm optimizer for improved global optimization and object tracking," Swarm and Evolutionary Computation, vol. 43, pp. 1-30, 2018.

[54] R. V. Rao, H. S. Keesari, P. Oclon, and J. Taler, "An adaptive multi-team perturbation-guiding Jaya algorithm for optimization and its applications," Engineering with Computers, vol. 36, no. 1, 2019.

[55] A. F. Nematollahi, A. Rahiminejad, and B. Vahidi, "A novel physical based meta-heuristic optimization method known as lightning attachment procedure optimization," Applied Soft Computing, vol. 59, pp. 596-621, 2017.

[56] G. Derringer and R. Suich, "Simultaneous optimization of several response variables," Journal of Quality Technology, vol. 12, no. 4, pp. 214-219, 1980.

[57] M. A. Díaz-Cortés, E. Cuevas, J. Gálvez, and O. Camarena, "A new metaheuristic optimization methodology based on fuzzy logic," Applied Soft Computing, vol. 61, pp. 549-569, 2017.

[58] J. Zhou, C. Li, C. A. Arslan, M. Hasanipanah, and H. Bakhshandeh Amnieh, "Performance evaluation of hybrid FFA-ANFIS and GA-ANFIS models to predict particle size distribution of a muck-pile after blasting," Engineering with Computers, vol. 2019, pp. 1-10, 2019.

[59] A. Foroughi Nematollahi, A. Rahiminejad, and B. Vahidi, "A novel multi-objective optimization algorithm based on Lightning Attachment Procedure Optimization algorithm," Applied Soft Computing, vol. 75, pp. 404-427, 2019.

[60] T. Zheng and W. Luo, "An enhanced lightning attachment procedure optimization with quasi-opposition-based learning and dimensional search strategies," Computational Intelligence and Neuroscience, vol. 2019, pp. 1-24, 2019.

[61] L. L. Howell, S. P. Magleby, and B. M. Olsen, Handbook of Compliant Mechanisms, Wiley, Chichester, UK, 2013.

[62] G. Hao and H. Li, "Extended static modeling and analysis of compliant compound parallelogram mechanisms considering the initial internal axial force," Journal of Mechanisms and Robotics, vol. 8, no. 4, 2016.

[63] G. Hao, F. Dai, X. He, and Y. Liu, "Design and analytical analysis of a large-range tri-symmetrical 2R1T compliant mechanism," Microsystem Technologies, vol. 23, no. 10, 2017.

[64] N. T. Tran, N. Le Chau, and T. P. Dao, "A new butterflyinspired compliant joint with 3-DOF in-plane motion," Arabian Journal for Science and Engineering, vol. 2020, pp. 1-15, 2020.

[65] T.-P. Dao and S.-C. Huang, "Design, fabrication, and predictive model of a 1-dof translational flexible bearing for high precision mechanism," Transactions of the Canadian Society for Mechanical Engineering, vol. 39, no. 3, pp. 419-429, 2015.

[66] S. García, D. Molina, M. Lozano, and F. Herrera, "A study on the use of non-parametric tests for analyzing the evolutionary algorithms behaviour: a case study on the CEC'2005 special session on real parameter optimization," Journal of Heuristics, vol. 15, no. 6, pp. 617-644, 2009.

[67] J. Derrac, S. García, D. Molina, and F. Herrera, "A practical tutorial on the use of nonparametric statistical tests as a methodology for comparing evolutionary and swarm intelligence algorithms," Swarm and Evolutionary Computation, vol. 1, no. 1, pp. 3-18, 2011.

[68] L. M. Li, K. Di Lu, G. Q. Zeng, L. Wu, and M. R. Chen, "A novel real-coded population-based extremal optimization algorithm with polynomial mutation: a non-parametric statistical study on continuous optimization problems," Neurocomputing, vol. 174, pp. 577-587, 2016.

[69] S. García, A. Fernández, J. Luengo, and F. Herrera, “A study of statistical techniques and performance measures for geneticsbased machine learning: accuracy and interpretability," Soft Computing, vol. 13, no. 10, pp. 959-977, 2009. 